\title{
La Sociolingüística de Redes y los Social Media
}

\author{
ESTHER JuAn EscriHUELA* \\ Universitat Rovira i Virgili, Tarragona, Spain
}

\begin{abstract}
In this paper, the model of Social Networks -proposed in 1987 by J. Milroy and L. Milroy- is applied to the analysis of linguistic interactions that happen in Facebook and Twitter, two social networks with a similar purpose but they behave in a different way and they provide different types of reticulated structures. The linguistic behavior of users of social media is studied in order to determine whether the general principles defensed in the reticular studies applied to the linguistic variation are achieved in the language used in digital platforms. Our results show that there is a big contrast between the linguistic characteristics that present the people who are part of a dense and multiple network-Facebook- and the ones that take part in a relaxed and simple network -Twitter.
\end{abstract}

Keywords: Linguistic analysis, reticulate structure, social network, Facebook, Twitter.

Resumen. En este trabajo, se aplica el modelo de Redes Sociales -propuesto en 1987 por J. Milroy y L. Milroy- al análisis de las interacciones lingüísticas que se producen en Facebook y Twitter, dos redes sociales con un propósito similar pero que se comportan de forma diferente y proporcionan distintos tipos de estructuras reticulares. Se analiza el comportamiento lingüístico de los usuarios de estas redes

\footnotetext{
* Author's address:

Departament de Filologies Romàniques

Universitat Rovira i Virgili

Av. Catalunya 35, 43002 Tarragona, Spain

E-mail esther.juan@estudiants.urv.cat
} 
con el objetivo de comprobar si los principios generales defendidos por los Milroy se cumplen en el lenguaje utilizado en las plataformas digitales. Los resultados obtenidos demuestran que existe un contraste entre los rasgos lingüísticos de los individuos que forman parte de una red densa y múltiple -el caso de Facebook- y los que conforman una red laxa y simple -el caso de Twitter.

Palabras clave: Análisis lingüístico, estructura reticular, red social, Facebook, Twitter.

\section{Introducción}

El impacto de las redes sociales en la actualidad es de magnitudes desorbitadas y su importancia en nuestro día a día parece innegable. Los datos son muy claros: el $82 \%$ de los usuarios de Internet tienen cuenta en Facebook, y este porcentaje supera el $90 \%$ en la mayoría de países desarrollados o en vías de desarrollo. Facebook posee 1.490 millones de usuarios activos, es decir, personas que se conectan al menos una vez al mes. Cada día, alrededor de 1.000 millones de personas se conectan a esta red social. Si tenemos en cuenta que se estima que la población internauta mundial es de 2.000 millones de personas, podemos afirmar que 3 de cada 4 internautas mundiales está en Facebook. Google+ es la segunda red con mayor número de usuarios, seguida de Twitter que es usada por un 50\% de los internautas, lo que representa unos 282 millones de perfiles en dicha red social. En el mundo, cada minuto se generan 684.478 piezas de contenido en Facebook y se publican 3.600 fotografías nuevas. Los usuarios de Twitter envían 58 millones de tuits al día, lo que significa unos 9100 tuits al segundo.

La Online Business School (OBS) ha realizado el "Estudio Social Media 2015 " en el que se analizan las tendencias de uso y participación en redes sociales tanto en España como en las principales economías mundiales. Centrándonos en los datos de nuestro país, la OBS indica que España, en el 2015, contaba con una población online de 23 millones de personas, de las cuales 17 millones utilizaban las redes sociales. Las tres redes más usadas por los españoles son, por este orden, Facebook, Google + y Twitter.

La empresa de comunicación y marketing The Social Media Family ha realizado "El I Estudio sobre los usuarios de Facebook y Twitter en España", que analiza el comportamiento de cincuenta ciudades españolas. Este informe indica que de los 20 millones de usuarios españoles registrados en Facebook, uno de cada cuatro tiene estudios universitarios y prácticamente existen los 
mismos perfiles de hombres que de mujeres. En el caso de Twitter, la cifra de usuarios gira en torno a los 3,5 millones de perfiles. El $88 \%$ de los españoles que usa Internet tiene Facebook frente al $87 \%$ del año anterior, igual que ocurre en el caso de Twitter, dicha red social también ha aumentado del $54 \%$ al $56 \%$ en un año.

Recientes estudios estiman que en 2018 los usuarios mundiales de redes sociales duplicarán los 1220 millones que había en el 2011, por lo que se prevén alrededor de 2400 millones de internautas mundiales.

Las redes sociales permiten establecer vínculos de índole diversa entre sus usuarios. Se crean relaciones de amistad, parentesco, vecindad, se comparten intereses y actividades con personas que están a miles de kilómetros, y son, cada vez más, una manera de hacer negocio para las empresas. Es tal la fuerza que tienen las redes sociales que son capaces de movilizar a sociedades enteras, como ocurrió con la Primavera Árabe o con el movimiento $15 \mathrm{M}$ que se produjo en España durante el 2015.

Dichos datos demuestran que pasamos horas conectados a Internet, interactuando a través de las redes sociales y, según informan recientes estudios, este uso está creciendo de forma exponencial.

Las redes sociales han abierto un camino nuevo en la comunicación que nos ha llevado a enormes variaciones en ella. El lenguaje evoluciona, está constantemente cambiando y adaptándose a las nuevas realidades de la sociedad y esto es hoy especialmente notorio en las diferentes redes sociales.

Las nuevas herramientas de comunicación digital nos obligan a utilizar el lenguaje de manera diferente. La capacidad de sintetizar y expresar las ideas de manera concisa es uno de los requisitos imprescindibles para cualquier internauta. Esto es especialmente importante en el caso del microblogging de Twitter que tan solo permite a los usuarios publicar 140 caracteres, lo que conlleva una búsqueda de ahorro de espacio en los mensajes. Esta restricción hace que, en muchos casos, los usuarios pongan el énfasis no en la corrección lingüística, sino en la posibilidad de expresar todo lo que quieren comunicar en el espacio que tienen a su disposición.

Especialmente relevante en esta nueva manera de usar el lenguaje es la separación que existe entre la comunicación oral y la comunicación escrita. Las nuevas formas de interactuar han supuesto una transferencia de las propiedades que caracterizaban el uso oral del lenguaje a la comunicación 
escrita. La importancia de este nuevo paradigma comunicativo es tan grande que creemos que el lingüista debe ocuparse de su caracterización.

En esta investigación, proponemos el análisis sociolingüístico del lenguaje utilizado en las redes sociales. Concretamente, nuestro interés recae en el modelo de Redes Sociales (Milroy \& Milroy 1985) aplicándolo a las emisiones lingüísticas que se producen en Facebook y Twitter. Aquí pretendemos observar si hay variación -y si es así, observar cómo se produce y por qué- entre las diferentes formas de comunicarse según el tipo de red que se crea entre los individuos que conforman cada una de estas plataformas digitales.

En general, los modelos propuestos por la sociolingüística han sido aplicados a interacciones orales, como hicieron J. Milroy y L. Milroy en 1987 con la Teoría de las Redes Sociales al utilizarla para analizar a la población de Belfast (Irlanda). Es por ello que resulta interesante ver si su modelo sigue siendo aplicable para describir la variación lingüística en las redes sociales virtuales.

Teniendo en cuenta la eficacia demostrada por el concepto de red social como factor de variación sociolingüística, nuestro objetivo es aplicar dicho modelo al análisis de las interacciones lingüísticas a través de plataformas digitales como Facebook y Twitter. En concreto pretendemos:

1. Analizar el concepto de red social en ámbitos diversos como son la sociología, la sociolingüística y la comunicación mediatizada por ordenador y establecer la relación entre los distintos usos.

2. Determinar y caracterizar los distintos tipos de redes sociales (en términos sociolingüísticos) que se forman en la comunicación a través de los social media.

3. Estudiar el comportamiento lingüístico de los usuarios de los social media a través del análisis de su integración en redes de diverso tipo.

4. Proponer una caracterización lingüística de los usuarios de los social media dependiendo del tipo de red social en la que se integren.

5. Comprobar si los principios generales defendidos en los estudios reticulares aplicados a la variación lingüística se cumplen en el lenguaje utilizado en redes sociales como Facebook y Twitter.

Para conseguir los objetivos que nos hemos propuesto, nuestro artículo se ha dividido en dos partes claramente complementarias: 
1. una parte teórica en que la que se ha analizado la bibliografía sobre redes sociales.

2. una parte empírica en la que hemos recogido y analizado un corpus de datos de interacciones en redes sociales.

La metodología de investigación que hemos seguido para alcanzar nuestros objetivos ha sido la metodología estándar. Específicamente:

1. Examinar las fuentes bibliográficas que nos proporcionan los datos teóricos necesarios para realizar nuestro análisis.

2. Seleccionar los informantes que van a proporcionar los datos lingüísticos que necesitamos para nuestro análisis.

3. Recopilar un corpus de datos a partir de las interacciones de los informantes seleccionados.

4. Determinar los distintos tipos de estructuras reticulares en las que se integran los informantes seleccionados.

5. Analizar el corpus de datos, estudiando los comportamientos lingüísticos de los informantes en función de su integración en redes de diferente tipo.

6. Comprobar si los principios generales defendidos en los estudios reticulares aplicados a la variación lingüística se cumplen en el lenguaje utilizado en Facebook y Twitter.

Nuestro análisis asume que el español, como la mayoría de lenguas, presenta variantes internas y que todo hablante al usar su lengua es consciente de que esta presenta posibilidades de variación en todos los niveles lingüísticos. De esta manera contemplamos que en todo acto sociolingüístico, cuando se construye, se emite y se interpreta, intervienen factores sociales y contextuales.

Para explicar la variación resulta imprescindible contar con datos objetivos de hablantes reales, por ello hemos seleccionado un conjunto de informantes, que responden a perfiles sociales diferentes, que nos proporcionarán los datos lingüísticos necesarios para construir un corpus a partir del cual realizaremos nuestro análisis.

Las redes sociales elegidas para nuestro análisis son Facebook y Twitter. Hemos optado por estas dos plataformas porque, como ya hemos señalado, 
son las que gozan de más éxito, cuentan con más usuarios y están en clara expansión.

El hecho de construir nuestro corpus a partir de datos obtenidos de dos redes sociales diferentes se debe a que estas no se comportan de la misma manera y, por ello, pueden proporcionar distintos tipos de estructuras reticulares en términos sociolingüísticos. Aunque la dinámica y propósito de Facebook y Twitter es similar -fomentar que sus usuarios puedan estar permanentemente conectados intercambiando información de todo tipo- el tipo de relaciones que se establecen en estas dos son distintas. Mientras que el peso específico de Facebook radica en la calidad de las relaciones de amistad que se construyen, Twitter pone el énfasis en la cantidad de seguidores que uno tiene. Twitter se usa para seguir a personas famosas o personas que nos interesan por algún motivo y de esta manera poder conocer más sobre ellas, sobre su día a día, saber de sus vidas privadas y de sus vidas profesionales. Facebook, en cambio, es una red social más íntima y privada en la que compartir aspectos de la vida con gente que conoces personalmente.

Otro aspecto que diferencia a estas dos redes sociales, y que puede ser relevante para nuestro estudio, es la privacidad. La red social Facebook permite que sean sus usuarios los que escojan qué información personal se muestra públicamente, quiénes son sus amigos y quiénes pueden ver sus publicaciones. Frente a esto, Twitter ofrece poca privacidad, se puede seguir y ser seguido sin ningún tipo de filtro o aceptación por parte del emisor del tuit, e incluso los contenidos pueden ser vistos sin formar parte de dicha plataforma.

Una vez escogidas estas dos redes sociales, hemos procedido a la selección de los individuos a utilizar como informantes. Aunque nuestro análisis no pretende ser de tipo cuantitativo, hemos creído conveniente compilar un corpus relativamente extenso que permita que los resultados obtenidos tengan la suficiente consistencia como para poder aportar ideas interesantes en nuestro ámbito de estudio.

Hemos seleccionado a 140 individuos y hemos recogido 15 intervenciones de cada uno de ellos. De esta manera, nuestro corpus está compuesto por un total de 2100 intervenciones, de las cuales 1050 proceden de Facebook y 1050 de Twitter.

Los individuos seleccionados en cada una de las dos redes sociales presentan características distintas: 
1. En el caso de Twitter, y contemplando los rasgos que se han señalado en las líneas anteriores, se han seleccionado 70 personajes conocidos públicamente que atraen a públicos muy diferentes, por lo que establecen redes sociales con nodos variados. Se trata de hombres y mujeres hablantes de español que son populares entre círculos muy diversos, de forma que encontramos:

- 14 cantantes de diferente estilo musical;

- 14 deportistas;

- 12 periodistas;

- 10 políticos;

- 4 actores;

- 3 modelos;

- 3 cocineros;

- 2 toreros;

- 2 rectores de universidad;

- 2 personajes de televisión;

- 2 humoristas;

- el Papa.

2. En el caso de Facebook, hemos seleccionado a 70 usuarios. Estos son 28 hombres y 41 mujeres con perfiles privados. Los podemos agrupar según su sexo y edad de la siguiente manera:

- 3 mujeres menores de 20 años;

- 28 mujeres entre 20-25 años;

- 8 mujeres entre 26-30 años;

- 2 mujeres mayores de 30 años;

- 20 hombres entre 20-25 años;

- 7 hombres entre 26-30 años;

- 2 hombres mayores de 30 años.

Además, podemos clasificar a estos usuarios según su nivel de instrucción:

- 33 estudiantes;

- 20 individuos con estudios superiores;

- 17 individuos sin estudios superiores.

Es importante insistir en que nos proponemos realizar un estudio cualitativo y no cuantitativo. La unidad de análisis no es el individuo sino el conjunto 
formado por los individuos y los lazos entre ellos. En la teoría de redes, la raza, la edad, el sexo o la categoría social importan mucho menos que las formas de las relaciones que mantienen. Son las relaciones, los vínculos que mantienen los actores, las que determinan cómo los individuos están conectados unos a otros en las diversas situaciones.

\section{Redes Sociales}

Actualmente, el concepto de "red social" ha adquirido una notable importancia. Se ha consolidado como una expresión muy común en nuestro día a día al estar acostumbrados a leerla y a escucharla, así como a emplearla con facilidad, pero siempre situándola en el contexto de las plataformas de comunicación online que están revolucionando nuestra forma de relacionarnos y de comunicarnos. En realidad, el nacimiento del concepto "red social" es mucho anterior a la aparición de Internet, de las nuevas tecnologías y de plataformas como Facebook o Twitter. Su significado es más amplio y complejo.

Las redes sociales han sido desde hace más de medio siglo objeto de estudio de diversas disciplinas como la sociología, la antropología, la filosofía, la sociolingüística, o las matemáticas. Este gran interés ha dado lugar a distintas teorías que varían según la ciencia que ha analizado el concepto. A pesar de las diferencias, todas las disciplinas que han considerado este concepto tienen en común que el centro de sus investigaciones sobre las redes sociales es el individuo y las relaciones personales que este establece con el resto del grupo.

En este apartado analizaremos el concepto "red social" desde tres perspectivas: la sociológica, la sociolingüística y la tecnológica.

\subsection{Red Social en Sociología}

La sociología fue la primera de las tres disciplinas que se interesó por las redes sociales de los individuos. Esta definió dicho concepto como un entramado de relaciones directas entre individuos, que actúa como mecanismo para intercambiar bienes y servicios, para imponer obligaciones y para otorgar derechos que corresponden a sus miembros (Milroy 1987: 7). Estamos ante relaciones entre individuos, no entre grupos. La estructura social que se crea está compuesta por un conjunto de actores sociales conectados por diadas, también 
conocidas como lazos interpersonales entre dos actores, que se pueden interpretar como diferentes tipos de relaciones en distintos niveles.

Estas redes son relaciones familiares, profesionales, de amigos, etc. que se van creando a lo largo de toda la vida del individuo y son, en gran parte, las responsables de formar su identidad, expresar su personalidad, estructurar sus relaciones y las que le hacen participar en ciertas interacciones sociales.

El origen de la teoría de redes se remonta a diversas perspectivas teóricas autónomas y paralelas, las cuales, con el paso del tiempo, se unieron para ofrecer la posibilidad de representar de forma gráfica las relaciones entre los actores.

En la base de la teoría de redes tradicional hay dos corrientes:

1. una sociocéntrica que desarrolla Georg Simmel (1908);

2. y una corriente egocéntrica, explicada por Radcliffe-Brown (1940), que se basa en la antropología social.

Simmel interpreta la idea de relación de la siguiente manera:

Una colección de seres humanos no deviene una sociedad solo porque cada uno de ellos sea dueño de un contenido de vida objetivamente determinado o subjetivamente determinante. Se convierte en una sociedad solo cuando la vitalidad de esos contenidos alcanza una forma de influencia recíproca; solo cuando un individuo posee un efecto inmediato o mediato sobre otro (Simmel 1908 [1971]: 24-25]).

Radcliffe-Brown (1940), el fundador del estructural-funcionalismo, escribió en 1940 que la estructura social australiana se basaba en una "red" de relaciones diádicas de persona a persona. Además, añadió que:

Una relación particular entre dos personas solo existe como parte de una amplia red de relaciones sociales, involucrando muchas otras personas, y es esta red lo que considero objeto de nuestras investigaciones. [...] En el estudio de la estructura social, la realidad concreta que nos interesa es el conjunto de relaciones realmente existente, en un momento determinado del tiempo, que vincula a ciertos seres humanos (Radcliffe-Brown 1940: 3-4). 
Fue en los años 50 cuando empezó a despertarse el interés por las redes de comunicación. El psicólogo social norteamericano Alejandro Bavelas (1951), siguiendo al especialista en psicología de grupos y relaciones interpersonales Lewin, propuso un modelo matemático basado en la teoría de grafos para describir y analizar las redes de comunicación. Esta teoría es uno de los pilares fundamentales del modelo de Redes Sociales que se estaba empezando a forjar.

Un grafo es un conjunto de puntos entre los cuales se definen relaciones simétricas, asimétricas, orientadas, múltiples o simples. Cada uno de ellos es la representación que admite una red, y a la inversa una red es a su vez una interpretación empírica de un grafo (Flament 1977: 54).

La teoría de grafos fue introducida hacia 1736 por el suizo Leonhard Euler. De sus interpretaciones se deriva que se pueden distinguir dos partes en un grafo:

\section{1. el conjunto de vértices o nodos}

2. y el conjunto de aristas

La teoría de grafos es la forma más genérica de representar las redes. Interpretamos los nodos como individuos y los vínculos como relaciones entre nodos, de manera que permite analizar las redes sociales existentes entre los amigos de Facebook y Twitter.

Harary (1956) impulsó la teoría de grafos dentro del análisis de redes sociales y promovió las matrices (álgebra de grupos) como instrumento para estudiar estas relaciones. A partir de autores como Cartwright, Moreno y Bavelas (1956) se derivó la explicación que defiende que en el análisis de redes solo hay dos clases primarias de entidades, los nodos y las conexiones, y cada autor puede utilizar los indicadores diacríticos que le convenga cuando lo necesite (Reynoso 2011:75).

A finales de los años sesenta, el antropólogo John Barnes (1969) conceptualizó la idea de red y creó el nombre exacto de "red social" sobre el sistema social de Bremnes (Noruega). Barnes se imaginó un conjunto de puntos, algunos de los cuales estaban unidos por líneas. Los puntos eran gente individual o grupos, y las líneas indicaban que la gente interactuaba. El antropólogo creó la noción de densidad, a partir de la idea abstracta de que un "alfa" (ego) en interacción con un "contacto" (alter) puede encontrar que este contacto esté, a su vez, en relación con otros de sus contactos. Todas las relaciones entre un ego y sus alters, adyacentes y no adyacentes, constituyen una "zona", que 
por extensión lógica se clasifica como de "primer orden", "segundo orden", etc. (Barnes 1969: 58-60). El problema es que en esta teoría, en algunas ocasiones, las relaciones resultaban incontrolables.
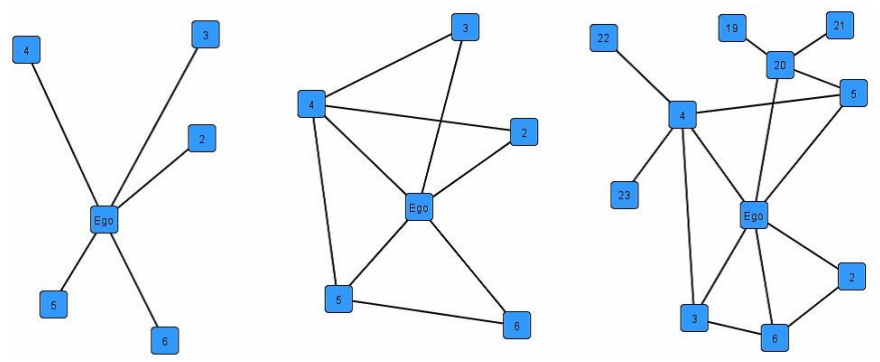

Fig. 1. Gráfico 1. Representación de la densidad en distintas zonas reticulares: 1Red social de primer orden; 2-Zona de primer orden; 3-Red social de segundo orden. Basado en Barnes (1969) (Reynoso 2011:106).

De la unión de las investigaciones de Barnes y las aportaciones de la teoría de grafos, se establece que cada actor construye relaciones sociales con otros individuos, los cuales también construyen su red de relaciones sociales con otros sujetos que pueden estar vinculados, o no, con el actor inicial.

Barnes demostró que las diferentes relaciones que cada actor crea pueden tener cierta influencia en el comportamiento del resto de individuos que forman su red. Además, el propio actor puede modificar la estructura de su red, según su conveniencia, para obtener sus fines. Con todo esto se demuestra que las redes son dinámicas y que los individuos son figuras indispensables en ellas.

\subsection{Red Social en Sociolingüística}

Durante los años setenta, el uso del concepto de red social experimentó un fuerte crecimiento gracias a su aplicación en la sociología. Es de aquí de donde lo toma la sociolingüística, con la finalidad de encontrar métodos de campo satisfactorios para el estudio del lenguaje en la sociedad.

Las redes sociolingüísticas consideran al individuo como punto de encuentro de una estructura que forma parte de la comunidad y en la que las normas 
lingüísticas son las encargadas de regular el intercambio comunicativo con los demás individuos que forman parte de ella (García Marcos 1999: 206).

Los hablantes tenemos libertad de elección para usar el lenguaje, que funciona como un mecanismo de identificación con los diferentes grupos sociales y en diferentes momentos. Cualquier comportamiento lingüístico presupone la identificación de un hablante con un grupo social concreto, de modo que se crean redes de comunicación que tienen rasgos lingüísticos peculiares, los cuales les caracterizan e identifican como red.

El concepto de red social se ha convertido en los últimos años en una herramienta útil para el análisis lingüístico, ya que mediante la estructura de una red y sus características se nos ofrecen explicaciones para ciertos fenómenos de la lengua, siendo la variación lingüística uno de los más destacados.

La metodología de las redes sociales ha aportado al desarrollo de la sociolingüística un instrumento más natural y real de acceso al hablante. Nos permite obtener una explicación de la variación vinculándola con variables como el modo de vida o la historia social de cada individuo. Por ello, se ha convertido en una de las vías más prometedoras para el análisis y la explicación de la realidad social y el lenguaje.

Los primeros estudios sociolingüísticos en los que se utiliza el concepto de red social vieron la luz en la década de los ochenta y desde entonces han ido en aumento.

El modelo de Redes Sociales, aplicado a los estudios sociolingüísticos, nació en 1987 de la mano de James Milroy y Lesley Milroy, quienes inauguraron un nuevo camino para la sociolingüística con su investigación realizada en la ciudad de Belfast (Irlanda). Este modelo toma principalmente como los estudios realizados por Lloyd Wayner (1940) y los trabajos de investigación de Elisabeth Bott (1957).

A partir de las investigaciones realizadas por Warner se empezó a ver cómo el entorno influía en las conductas de los actores. Como consecuencia apareció la teoría de la fuerza de los lazos débiles. Esta determina que las personas con las que un sujeto tiene menos contacto - son solo conocidos (lazos débiles) - es menos probable que estén implicadas socialmente entre sí. Por el contrario, los amigos íntimos (lazos fuertes) sí que establecen relaciones. De este modo, el conjunto de personas formado por un individuo y sus conocidos constituirá una red de baja densidad, donde muchas de las líneas posibles 
de relaciones están ausentes; mientras que la red del conjunto formado por ese mismo individuo y sus amigos más íntimos será densa (Granovetter 1982).

Elisabeth Bott (1957) centró sus trabajos en la vinculación de los roles entre marido y mujer y su variación directa con la red social de la familia. Bott distinguió dos tipos básicos de redes en relación con las parejas:

1. redes de tejido cerrado formadas por familias obreras que vivían en los mismos barrios donde habían nacido, tenían relaciones sociales anteriores a la formación de la familia y en las que la gente se conocía en varias facetas;

2. redes de tejido abierto formadas por familias de clase media, que habían cambiado en alguna ocasión de lugar residencial y que tenían relaciones sociales nuevas, cambiantes y sin ninguna conexión con relaciones sociales anteriores.

A partir de las investigaciones de Bott, se defendió que cuando un individuo está fuertemente ligado a otros, que también están ligados entre sí, todos tienden a alcanzar consenso y a ejercer cierta presión sobre el resto de individuos con la finalidad de alcanzar conformidad con las normas, estar en contacto entre ellos y poder ayudarse. Por el contrario, si los vínculos son esporádicos, resulta más improbable que se establezcan estas normas. Vemos pues que, cuando más densa y múltiple es la red de un individuo, mayor es su capacidad para imponer sus normas de conducta lingüística, mientras que si las relaciones son más débiles y escasas, la capacidad del individuo para imponer sus normas al resto de grupo es muy reducida.

\section{Modelo de Redes Sociales}

El Modelo de Redes Sociales parte de la hipótesis de que la proximidad a las normas lingüísticas vernáculas se correlaciona positivamente con el nivel de integración individual en las redes de la comunidad local correspondiente.

El principio básico de esta teoría es que el comportamiento social es esencialmente un intercambio de bienes materiales y no materiales, entre los que se encuentran los símbolos de aprobación o prestigio. De esta manera, las relaciones son consideradas transacciones y cuando estas se producen en ambas direcciones, estamos ante casos de intercambio y la mayor parte de los hechos de habla son de este tipo. 
El análisis de las redes sociales centra su atención en dos elementos fundamentales, los actores y los vínculos:

- Los actores se identifican con una serie de variables sociales (edad, sexo, nivel de instrucción, profesión, raza y etnia). Cada actor crea su red al establecer vínculos directos con un conjunto de actores, los cuales a su vez también van construyendo vínculos, de forma que todas las redes personales dan lugar a la red social general.

Los actores escogen el tamaño, la composición y el carácter de su red. Aunque esta libertad está limitada por el conjunto de personas que forman el entorno, las reglas de su sociedad, el contexto y los límites de su personalidad.

- Los vínculos están determinados por su contenido y por su estructura. El contenido hace referencia a la función de la relación y al objeto que se transmite mediante ella. Se puede considerar que existe una relación cuando las personas están vinculadas entre sí en la medida en que están continuamente interactuando e intercambiando algo los unos con los otros (Fischer 1982:35).

La estructura o forma de los vínculos está condicionada por el número de sujetos que la forman y la fuerza que une a los actores. Estos criterios se miden mediante índices indicadores de densidad y de multiplicidad.

La densidad depende del grado en el que la gente que constituye la red social se conoce:

- Una red es de densidad alta si el actor en el que está anclada está vinculado a un gran número de personas, las cuales a su vez están vinculadas con otros actores. Son redes homogéneas y más pequeñas que las de densidad baja, porque los lazos que vinculan las relaciones limitan que se creen más. Sus miembros son menos partidarios de desarrollar vínculos exteriores a la red. En este tipo de estructura los vínculos entre los actores son más estables y duraderos.

- Las redes de densidad baja son más grandes y heterogéneas. Sus miembros tienen alternativas de desarrollar relaciones que no se solapen con otros individuos. Se crean vínculos menos estables que en las redes más densas debido a que los actores saben menos unos de otros y hay una menor interdependencia entre ellos. (Salzinger, citado en Requena Santos 1995: 57-58) 
La multiplicidad se define como la proporción de las relaciones múltiples con respecto a todas las relaciones relevantes. El contenido de las relaciones puede dar lugar:

- a una red simple, si esta está formada por un solo vínculo;

- a una red múltiple, si existen varios vínculos simultáneos, es decir, si hay varios tipos de relaciones entre dos o más actores.

La densidad y la multiplicidad son excelentes indicadores de la presión de la red sobre el individuo, la cual le lleva a adoptar o no las normas y valores de la comunidad.

La red de estructura densa y múltiple o red fuerte es aquella en la que todos los sujetos están enlazados e interactúan entre ellos a través de más de un vínculo. Se caracteriza por un alto grado de conformismo lingüístico, lo que conlleva comportamientos lingüísticos vernáculos y como consecuencia las diferencias entre los grupos se acentúan y los miembros se aíslan de las influencias externas (Santos y Muñoz, 2002: 77). Cuanto más densa es la red, más homogéneos son los usos lingüísticos para lograr identificarse con el grupo (Canales 2000: 117).

La red de estructura poco densa y simple o red laxa no impide la diversificación del habla de sus miembros. Esta se caracteriza por el poco conformismo lingüístico que muestran sus actores, los cuales actúan de acuerdo a las pautas nacionales y a la norma general, dejando de lado los patrones locales.

\section{Estudio realizado por Lesley Milroy (1987)}

La idea de utilizar el concepto de red social como una variable del hablante fue introducida por Lesley Milroy (1987) en su estudio en la ciudad de Belfast. El tipo de estudio reticular que propuso no necesitaba establecer fronteras ni entre los grupos ni dentro de ellos y por tanto, siguiendo este procedimiento, cualquier individuo podía ser objeto de la investigación, perteneciese o no de forma consciente a uno de los grupos analizados.

La investigación de Milroy se basaba en explicar el comportamiento lingüístico de 46 hablantes de la clase trabajadora de Belfast, pertenecientes a 3 comunidades distintas. Se caracterizaban por su habla vernácula y por el mantenimiento de los valores grupales. 
La hipótesis de la que partía Milroy era que la proximidad a las normas lingüísticas vernáculas está relacionada con la integración del individuo en la red de su comunidad. A partir de dos estilos lingüísticos, analizó una serie de variables fonológicas en el habla de los sujetos.

La medición se llevó a cabo combinando la multiplicidad y la densidad en las relaciones individuales. De esta forma, se intentó hacer una valoración cuantitativa del grado en el que la estructura de la red individual predijese la conducta lingüística de cada persona.

La medida usada en [...] Belfast para examinar la relación entre la variación lingüística y la estructura de la red fue una escala de seis puntos que medía los índices de los hablantes sobre cinco indicadores de multiplicidad y densidad (vecindad, parentesco, trabajo en el mismo lugar que otros vecinos, trabajo en el mismo lugar que otros vecinos del mismo sexo y amistad). Estos indicadores fueron interpretados como requisitos que, si se cumplían, sugerían la existencia de una red personal relativamente densa y múltiple. A cada individuo se le asignaba un punto por cada requisito que cumplía, de tal forma que el grado de fuerza de la red era la suma de los índices de los indicadores individuales. (Milroy 1987: 106).

Las técnicas estadísticas utilizadas en el análisis de L. Milroy para medir la integración comunitaria de los individuos y la influencia que tiene esta en su actitud lingüística son la correlación y el análisis de la varianza. Conjuntamente pueden mostrar una relación cuantitativa entre variables lingüísticas y extralingüísticas.

La correlación es una prueba que mide la utilidad de la escala de fuerza de la red entera. Se trata de una prueba estadística que examina la relación entre las puntuaciones crecientes de variables lingüísticas y las puntuaciones crecientes también en la escala de fuerza de la red.

Por otro lado, el análisis de la varianza puede comprobar al mismo tiempo y por separado la importancia de la diferencia entre las puntuaciones de las variables lingüísticas de varios subgrupos y la relación con las puntuaciones altas y bajas de la escala de fuerza de la red.

El análisis estadístico demostró que existe una importante relación positiva entre la escala de fuerza de la red y cinco de las ocho variables lingüísticas estudiadas. 


\subsection{Red Social en Internet}

La aparición de Internet en 1969 en California (Estados Unidos) cambió de manera drástica la concepción que se había tenido hasta el momento de las redes sociales. Todo el conjunto de lo que entendemos por "Internet" es en sí mismo una red, pues este se define como una red informática mundial, descentralizada, formada por la conexión directa entre computadoras mediante un protocolo especial de comunicación (DRAE 2015).

Resulta obvio señalar la importancia que en la actualidad tiene Internet en nuestra actividad diaria, pero en el momento de su nacimiento este supuso una completa revolución en muchos aspectos, especialmente en la comunicación. Las conexiones que con él se establecieron nos permitieron comunicarnos, cooperar y participar en el mundo de una manera que no se había visto hasta el momento. Esta gran red permitió que los individuos se conectaran entre sí superando cualquier barrera física que pudiera existir.

Podemos definir las redes sociales en Internet como estructuras sociales compuestas por grupos de personas conectadas por uno o varios tipos de relaciones de amistad, parentesco, intereses, etc. A través de estas plataformas digitales se producen encuentros sociales, en tiempo real o en diferido, que consiguen establecer lazos entre personas de diferentes clases sociales, culturas, religiones, ideas políticas, etc. (Ayala 2012: 397).

En inglés existen dos etiquetas para referirnos al término "Redes sociales en Internet": social networks y social media. Son términos muy relacionados entre sí, hasta el punto de considerarse inseparables, ya que el uno sin el otro no existiría.

- Los social networks se definen como las estructuras de relaciones entre individuos o grupos. Es decir, hace referencia a las redes de relaciones que se forman dentro de los social media. Se trata de nodos de interconexión social, de manera que el individuo interconecta y participa en la creación de una red de relaciones bidireccional en la que está implícita la pertenencia a un contexto cultural o social común (De Rivera 2011).

- Los social media se definen como un grupo de aplicaciones basadas en Internet que se desarrollan sobre los fundamentos ideológicos y tecnológicos de la web 2.0, y que permiten la creación y el intercambio de contenidos generados por el usuario (Ponce 2012: 2). Con el adjetivo social se indica 
que estos medios de comunicación están basados en relaciones entre sujetos, las cuales se establecen generando vínculos a través del medio de comunicación ("media"), y estos vínculos a su vez generan redes sociales.

Se trata de un proceso recíproco que confirma que son términos diferentes pero inseparables, dado que no podría existir uno sin el otro.

La web 2.0 ha contribuido a la aparición de programas con interfaces de usuario que permiten y facilitan la comunicación masiva y multidireccional, y así se han formado las redes sociales de Internet. El individuo ya no es un simple consumidor, sino que se convierte en el protagonista de la red con sus interacciones en ella y con el resto de individuos que participan. Las plataformas digitales son herramientas que cobran vida cuando los individuos les aportan contenido, ya que sin su presencia estas no existirían.

\section{Caracterización y Clasificación de los Tipos de Redes}

El análisis de las redes sociales se ha convertido en un método que permite visualizar, estudiar e interpretar las diferentes estructuras sociales construidas a partir de las relaciones constituidas en los intercambios.

Las redes sociales en Internet son un perfecto simulador de los vínculos que se crean en la sociedad real. Pues en estas se reflejan las conductas, interacciones e intercambios que se producen en la estructura social, e igual que en ellas, no todas son del mismo tipo.

Las dos redes sociales que aquí se han tomado, Facebook y Twitter, han cautivado a millones de personas en todo el planeta, sin distinciones intelectuales, idiomáticas o socioculturales. El hecho de que en ellas participen actores de distintas características sociales conlleva que se construyan conexiones diferentes entre estos individuos.

Tras analizar el corpus que hemos recopilado, hemos podido extraer las características de las conexiones que se establecen entre los individuos que forman parte de ambas redes sociales.

Como hemos explicado en apartados anteriores, el análisis de las redes sociales centra su atención en dos elementos fundamentales: los vínculos y los actores. Los vínculos se miden a partir de los indicadores de densidad y de multiplicidad de la relación y nos permiten caracterizar y clasificar los tipos redes en dos grandes bloques: 
1. Redes fuertes: presentan una estructura densa y múltiple. El actor que pertenece a este tipo de red está vinculado a un gran número de personas a las que conoce. A su vez, estos individuos se conocen entre ellos. Además, dichos sujetos interactúan entre sí de diferentes maneras porque entre ellos hay más de un tipo de vínculo.

2. Redes laxas: presentan una estructura poco densa y simple. El actor que pertenece a este tipo de red está vinculado a un gran número de personas, pero estos individuos no se conocen entre ellos. El único vínculo entre los individuos que forman estas redes es el que les une con el propio actor.

Los actores de las redes se caracterizan por las variables sociales. En este corpus se han recopilado datos de sujetos masculinos y femeninos, de diferentes edades, de distinta procedencia geográfica, con distinto nivel de instrucción y con diferentes profesiones.

El contenido de las relaciones que estos individuos establecen, es decir, la función de la relación y el objeto que se transmite mediante el vínculo, son diferentes según estemos en una red laxa o en una fuerte:

- En el caso de la red fuerte, los sujetos establecen a la vez relaciones formales, de comunicación, instrumentales y sentimentales. Estos actores se relacionan entre sí de forma mutua y recíproca, ya que son amigos, familiares, compañeros de trabajo y vecinos que interactúan en la red con la finalidad de trasmitir información de su día a día, ayudarse y consolidar su relación.

- Por el contrario, la red laxa ofrece relaciones de comunicación, habitualmente unilaterales, en las que un actor ofrece información sobre sí mismo sin esperar ninguna reacción por parte de los receptores del mensaje, comúnmente, ni siquiera una respuesta.

\subsection{Tipos de Redes en Twitter}

$\mathrm{Al}$ analizar a los actores que establecen comunicación vía Twitter se observa que estos presentan una estructura reticular laxa, es decir, poco densa y simple. Los individuos que forman parte de la red de un actor no mantienen ninguna conexión entre ellos más allá del vínculo que les une, es decir, el propio sujeto protagonista de la red. 
Se trata de redes grandes y heterogéneas, en las que no se conocen todos sus miembros, ni todos comparten características sociales entre ellos. Posiblemente lo único que tienen en común es el vínculo que les une, que en el caso de nuestro corpus es el interés por seguir la información que publica cierto sujeto en Twitter. Es por ello que los vínculos que se han creado aquí son muy poco estables, pues los actores saben muy pocos datos unos de otros y la interdependencia entre ellos es nula, lo que implica que las relaciones se pueden extinguir con facilidad.

Es frecuente en este tipo de redes que los individuos establezcan vínculos con más actores que configuran su red pero que no coinciden entre ellos, lo que reafirma la idea de que el único elemento común es un nodo.

En la mayoría de las redes de Twitter la relación es unilateral y por lo tanto no es recíproca. De manera que es uno de los actores el que decide que quiere establecer un vínculo con otro actor sin que este tenga que aceptar dicha conexión ni tampoco construirla y fomentarla de forma inversa. Como consecuencia de ello, solo uno de los nodos es el que recibe información sobre el otro actor por lo que la comunicación que se establece es solo de ida y por tanto, lo más común en Twitter es que no exista respuesta al mensaje.

En el caso de los individuos que se comunican mediante tuits, es relevante el número de seguidores que cada actor tiene, pues estos condicionan su actitud lingüística. Por ello hemos establecido la siguiente gradación que nos ofrece tres grupos en los que enmarcamos a los actores que hemos seleccionado para el análisis de este trabajo.

- Grupo 1: formado por actores que tienen entre 655 seguidores y $250 \mathrm{~K}$ (250.000).

- Grupo 2: formado por actores que tienen entre $251 \mathrm{~K}$ y $999 \mathrm{~K}$.

- Grupo 3: formado los actores que tienen más de 1M (1 millón) de seguidores.

\subsection{Tipos de Redes en Facebook}

Al analizar a los actores que interactúan en Facebook se observa que estos presentan una estructura reticular fuerte, es decir, muy densa y múltiple. Cada individuo mantiene distintos tipos de relación con sus amigos en dicha red social, pues estos son a la vez amigos y familiares o compañeros de trabajo, 
vecinos, etc. y además, cada uno de ellos suele establecer más nodos con otros sujetos.

Las redes densas que se ven en Facebook son homogéneas y más pequeñas que las de densidad baja, porque los lazos tan fuertes que unen las relaciones imposibilitan que se vayan creando más vínculos con facilidad. Las relaciones dentro de las redes densas sí que conducen a crear más vínculos, pero siempre dentro de la propia comunidad, es decir, los actores crean nuevas conexiones a partir de los vínculos que tienen sus mismos contactos y lo que evitan es desarrollar relaciones que los vinculen con el exterior de la red.

Una de las ventajas de estas redes es que los vínculos que se crean, a pesar de ser menores cuantitativamente, son más estables y duraderos debido a que los individuos están conectados entre sí por más de un motivo.

\subsection{Facebook versus Twitter}

La alta multiplicidad y densidad que ofrece Facebook frente a la baja multiplicidad y densidad que muestra Twitter hace que ambas redes sociales muestren muchas diferencias entre ellas.

\section{Rasgos diferenciales}

El nombre. El nombre Facebook traducido literalmente del inglés al español significa "libro de caras". Mark Zuckerberg, un estudiante de la Universidad de Harvard, creó en 2004, un listado web en línea de las imágenes de los universitarios. Gracias a la creación de Zuckerberg, todos los integrantes de las fraternidades de la Universidad estaban reunidos en una plataforma que les permitía comunicarse entre ellos.

La definición americana de "Twitter" ofrece dos acepciones: por un lado significa "una corta ráfaga de información intrascendente" y por otro, se refiere a "los sonidos emitidos por los pájaros". Ambas acepciones encajan perfectamente con la función para la que fue creada esta red social y por ello se tomó este nombre.

El logotipo. El logotipo de Facebook es un nítido cuadrado azul con el nombre de la red social inscrito en blanco. Pero si existe un símbolo que se ha hecho famoso desde la aparición de esta red social, es el dedo pulgar 
de la mano derecha alzado, que se emplea para indicar que algo gusta. Hacer clic en este "me gusta" es una forma simple de decirle a alguien que es de tu agrado, sin tener que dejar explícitamente un comentario. Es significativo que hasta el año 2015 no existiese una opción para mostrar descontento. Posiblemente no era muy oportuna esta alternativa en una red que tiene como finalidad fomentar las amistades.

El pájaro azul es el logotipo de Twitter, el cual se diseñó a partir del significado del término que se ha explicado en líneas anteriores. Además, los pájaros son aves pequeñas que revolotean deprisa y que parece que siempre están en movimiento. Esto se puede relacionar metafóricamente con los breves mensajes sin orden que se publican en esta red social.

Debemos destacar la diferencia entre las dos redes. El logotipo de la primera está asociado con atributos humanos, frente al animal que caracteriza a Twitter, el cual despersonaliza la red social y ofrece rapidez, movimiento y brevedad.

La función. Facebook se constituye como una herramienta que posibilita que los individuos que se conocen en la vida real, estén en el lugar del mundo que sea, puedan mantener una comunicación más allá de la relación física (Faerman 2010: 19). El usuario no acude a este espacio con la intención de ampliar sus ámbitos de socialización más allá de su círculo, sino que pretende reforzar los vínculos que ya tiene establecidos.

Twitter es una herramienta de información que permite conocer, en tiempo real, lo que está pasando en el mundo. Twitter sirve para distribuir y compartir información, para estar enterado de todo lo que interesa a un sujeto, para compartir ideas y para saber qué piensan los demás casi de inmediato sobre cualquier cosa (Tascón \& Abad 2011:12).

La pregunta inicial. La actividad principal de Facebook es escribir estados en el espacio que indica "¿Qué estás pensando?". La pregunta que la plataforma digital formula apunta directamente al pensamiento del individuo, es decir, a la parte más íntima del actor.

Twitter pregunta a sus usuarios “¿Qué está pasando?”. Es una forma más impersonal de saber qué ocurre alrededor del actor o incluso, lo que está sucediendo en el mundo en general, sin importar si esto está cerca o lejos del emisor. 
El emisor. Facebook nos ofrece la información más íntima y personal de nuestros amigos. A través de la plataforma, se puede saber todo sobre una persona únicamente por el hecho de agregarla a nuestra red: foto de perfil, nombre, edad, lugar de nacimiento, ubicación actual, estado civil, familiares, lugar donde estudió y trabajó, profesión, gustos, intereses, aficiones, creencias religiosas, etc. Además, es posible ver el listado de amigos que tiene, la zona destinada a las publicaciones generadas por el propio actor y los comentarios de otros usuarios, referidos tanto al texto de dichas publicaciones, como a imágenes o videos.

En el caso de Twitter la información que cada actor muestra consta de una foto, el nombre y una breve descripción en la que cada uno incluye aquello que desea. En este caso también es posible ver quiénes son los seguidores del actor y a qué usuarios sigue.

El receptor. Facebook es la extensión electrónica de grupos de conocidos físicos, por lo que la plataforma está dirigida a continuar y reforzar las redes sociales ya existentes. Los individuos saben a quién dirigen su mensaje, ya que son ellos mismos los que controlan quiénes forman parte de su red.

En el caso de Twitter, la comunidad virtual que se crea no tiene correlaciones específicas en el mundo físico, por lo que si la tecnología desaparece, la comunidad se extingue. Esta plataforma favorece la interacción virtual con otros actores con los que es muy improbable llegar a coincidir en un contexto físico. Los sujetos que emiten un tuit no saben quiénes son los receptores de este, puesto que su audiencia es desconocida, ya que cualquiera que tenga un perfil dentro de la red social les puede seguir porque estén interesados en sus publicaciones. El hecho de que el autor no tenga control sobre qué relaciones, lazos y amigos forman parte de su red social conlleva que los lectores anónimos tengan entornos cognitivos imprevisibles y los resultados interpretativos puede que no sean los que el emisor pretendía transmitir.

La temática. Facebook nos traslada la dimensión más personal e íntima de los usuarios con los que se establece el vínculo.

Las motivaciones que llevan a un usuario de Twitter a otro a seguir son más claras, pues están motivadas por los intereses o gustos del actor.

La amistad. En el caso de Facebook, todas las relaciones interpersonales de diferente tipo son por reducción asimiladas unívocamente a la misma 
categoría, restándole importancia a las características distintivas de cada caso particular.

Un rasgo muy característico de Facebook es que ofrece "sugerencias" sobre individuos que interactúan en la red y con los que un actor puede establecer comunicación. Es un listado de gente que la plataforma muestra porque considera que el usuario puede conocerlos. Estas sugerencias se basan en los aspectos personales o gustos que uno ofrece en su propio perfil o en los amigos en común. De esta forma, los actores se convierten en "amigos" y pasan a formar parte de la red social del otro. Esta posibilidad hace que todos los amigos de nuestro "amigo" puedan pasar a ser nuestros amigos y así ampliar los vínculos, aunque estos siempre se creen dentro de la misma comunidad.

En Twitter, los usuarios que forman parte de la red social de un actor se conocen como "seguidores". En este caso el concepto de amistad es muy laxo, cualquiera puede poner a otro usuario en su lista de seguidos sin que exista alguna relación o autorización del actor.

La reciprocidad. En Facebook, la amistad se crea en los dos sentidos ya que es reciproca porque ambos individuos comparten alguna parcela de la vida real. Estos vínculos comunes son los inicios que proporcionan la continuidad de posteriores interacciones.

Twitter es una red social unilateral, ya que un sujeto puede seguir a un individuo, pero este último no tiene por qué seguir al primero, es más, es posible que no sepa ni del seguimiento que tiene. Existe una opción que se podría interpretar como reciprocidad, es la conocida como "retweet". Esta permite a los usuarios citar tweets de otros individuos, lo cual crea reciprocidad en la aplicación ya que el autor puede ver qué sujeto ha copiado su tuit, y además los amigos del que retuitea verán la publicación original como si ellos mismos siguiesen al autor originario de esta.

La extensión del mensaje. La extensión de los mensajes, conocidos en Facebook como estados, entradas o publicaciones, no tiene límite de caracteres.

En el caso de Twitter, los mensajes emitidos reciben el nombre de tuits y estos tienen una extensión máxima de 140 caracteres, por lo que la brevedad es vital en esta red social. 
La privacidad. En Facebook es el actor el que determina quién puede leer sus publicaciones, comentarlas, ver sus fotos, su lista de amistades o su perfil de información. Esta privacidad se tambalea al poder compartir publicaciones escritas por un actor que forma parte de tu red social, pero no de la de todos tus amigos, los cuales también la podrán ver y comentar. Este rasgo proporciona a la red social una densidad muy alta ya que permite establecer vínculos entre actores desconocidos pero con una amistad en común, el nodo que los une.

La privacidad de Twitter es bastante reducida ya que permite ver los tuits sin ni siquiera pertenecer a la red, por lo que la densidad de esta es mucho más baja que la de Facebook.

\section{Rasgos Comunes}

- Son herramientas de comunicación y relación caracterizadas por su dinamismo.

- Los usuarios son el elemento clave de todo el sistema.

- Las comunidades virtuales son un grupo de personas que comparten intereses, interactúan y crean nuevos contenidos que se trasmiten mediante una infraestructura tecnológica.

- El perfil y los comentarios generan una identidad del actor e indican su identidad grupal, lo que sirve al resto de usuarios para crearse una idea del estatus del actor.

- Los usuarios tienen la necesidad de estar conectados con los otros nodos.

- Generan conexiones entre los usuarios que son visibles para el resto de individuos.

- La información se puede presentar en múltiples formatos.

\section{Diferentes Tipos de Red: Análisis Lingüístico}

Las redes sociales son un medio electrónico, global e interactivo, y cada una de estas propiedades tiene consecuencias para el tipo de lenguaje que en ellas se emplea. En Internet conviven consideraciones técnicas que influyen en 
la escritura, como el hecho de que las opciones comunicativas de un usuario estén limitadas por el conjunto de caracteres que el teclado ofrece, y también elementos puramente estéticos, así como otros que forman parte de una necesidad de diferenciarse de otros colectivos sociales y culturales (Tascón \& Abad 2011:35). Lo que pretendemos mostrar con nuestro análisis es que las relaciones que se establecen en las diferentes redes sociales determinan el comportamiento y las intenciones de los diversos actores sociales y esto se puede percibir a través de las características lingüísticas que poseen los enunciados que los individuos emiten.

A continuación analizamos las redes fuertes - características en Facebooky las redes laxas -típicas en Twitter- con el objetivo de proponer una caracterización lingüística de cada una de ellas que tenga en cuenta rasgos fonéticoortográficos, léxicos, morfosintácticos y pragmáticos.

\subsection{Redes Fuertes: Redes Densas y Múltiples}

Los rasgos lingüísticos que ofrece la comunicación escrita en las redes densas y múltiples se caracterizan por compartir muchos aspectos con el lenguaje oral. Los mensajes que se publican en este tipo de redes no se caracterizan por su elaboración premeditada y revisada. Se trata de una plasmación por escrito del pensamiento del individuo, el cual se materializa a la misma velocidad que se desarrolla en la mente del actor.

Una diferencia que puede parecer fundamental entre la oralidad y la escritura de las redes sociales es que los individuos que se vinculan no comparten un espacio físico. Ahora bien, en el caso de las interacciones en Facebook, a pesar de que los participantes no estén presentes en el mismo lugar, sí que comparten un mismo medio en el que construir, desarrollar y fomentar el vínculo. Además, igual que en las conversaciones orales, el emisor tiene en mente a un destinatario concreto, o a varios, a los que dirige su mensaje y de los que habitualmente espera una respuesta o una reacción.

El hecho de que la comunicación en Facebook se produzca sin mucha planificación y se desarrolle entre individuos que están conectados por más de un vínculo favorece la confianza entre los hablantes y la relajación en la comunicación. La relación vivencial de proximidad, es decir el conocimiento mutuo y la experiencia común compartida por los individuos es uno de los factores determinantes para que en las redes fuertes el estilo de la comunicación sea espontáneo y distendido y para que el estilo de la conversación sea informal. 
Los factores señalados favorecen el estilo coloquial entre los actores. Todos ellos comparten el mismo escenario ya que Facebook es la plataforma común. Entre los participantes existe una relación de igualdad y solidaridad. Existen unos propósitos comunes a la hora de establecer la comunicación. Y los temas que se tratan son accesibles y conocidos por todos los participantes.

Las estructuras de red múltiple y densa contribuyen a mantener las normas locales. Tienden a emplear rasgos vernáculos y a usar poco las formas propias del habla estándar. Posiblemente, esto ocurre porque los individuos están relajados, sin presión por la opinión que el receptor pueda tener de ellos o la imagen que puedan ofrecer. Además, el uso de las características vernáculas del grupo se presenta como un símbolo de identidad, pertenencia y lealtad a la comunidad de la que forman parte.

Los individuos que forman parte de la conexión creada dentro de una red densa y múltiple mantienen entre sí relaciones muy estrechas que les llevan a desarrollar conductas lingüísticas muy similares.

Cuando A y B interactúen se producirán tipificaciones con suma rapidez. A observará a $\mathrm{B}$. Atribuirá motivos a los actos de $\mathrm{B}$ y, viendo que se repiten, tipificará los motivos recurrentes. (...) En el curso de su interacción, estas tipificaciones se expresarán en pautas específicas del comportamiento; o sea, que A y B empezarán a desempeñar roles vis à vis uno del otro. (Berger y Luckmann 1968: 78)

De las características enumeradas se deriva que las redes múltiples y densas -como las que se crean en Facebook- son un perfecto mecanismo para imponer normas ya que cuando algún individuo de la red actúa lingüísticamente de determinada manera, este modelo va a ser repetido por los demás individuos con los que se vinculan. Las redes fuertes son una plataforma con capacidad para difundir entre la comunidad cualquier cambio, sea este normativo o no.

\section{Rasgos fonético-ortográficos}

Uno de los rasgos más llamativos de Facebook en el plano fonético ortográfico es la gran cantidad de recursos de abreviatura. Esto resulta significativo ya que en ella no hay un límite de caracteres. Probablemente, la razón que lo justifica sea la espontaneidad y rapidez.

Esta abreviación se puede llevar a cabo mediante diferentes recursos: 
- Se puede producir un truncamiento de la palabra al eliminar la parte final de esta, como ocurre en "japo" por japonés, en "vibra" por vibraciones o "peque" por pequeño.

No únicamente se truncan palabras, sino que también se truncan expresiones, ya que estas son tan conocidas por el receptor que el emisor sabe que las va a poder interpretar aunque no estén completas. Un ejemplo es la frase "Feliz día de los enamorados, mi media". Observamos que, a pesar de no estar la expresión final acabada, se puede deducir perfectamente por el contexto que el emisor pretendía transmitir la frase hecha " $m i$ media naranja".

- Puede darse una contracción del término eliminando las letras centrales de la palabra y dejando escritas las más significativas. Habitualmente se suprimen las vocales como ocurre en el adverbio " $t m b n$ " por también o en "tnido" para referirse a tenido, así como en "mñn" por mañana o "mvl" por móvil.

Uno de los ejemplos más repetidos es el de "pq" para expresar porque, por que, o por qué.

Otra contracción muy popular es la de "pal" por la construcción para él. En ella se ve una clara influencia de la fonética propia de la oralidad más coloquial que ha traspasado fronteras y se emplea también en la escritura relajada y distendida, ya que además de mostrar cercanía con el receptor, ahorra caracteres.

- Del recurso anterior se desprende la creación de silabogramas. Consiste en que una consonante sustituya a una sílaba entera porque el sonido de la pronunciación [consonante + vocal] es igual que el de la pronunciación de la consonante sola. Ocurre, por ejemplo, en la preposición de que pasa a escribirse "d", también la conjunción que como "q", "kiero" por quiero, "spro" por espero o es que el cual aparece en repetidas ocasiones escrita con la forma breve " $s q$ ".

- Es muy frecuente que se produzcan reducciones gráficas de las palabras basándose en la fonética de las letras, como ocurre en "muxo" por mucho, en "wapo" por guapo, o también en "xica" por chica.

El acortamiento de la palabras es uno de los recursos más empleados para abreviar. Uno de los casos que más se repite en el corpus analizado es el de fin de semana que pasa a ser "finde". Otros acortamientos que 
se observan son el de "face" para referirse a Facebook, "cole" por colegio, "cumple" por cumpleaños o "cuatri" por cuatrimestre.

- Se prefieren las formas abreviadas de palabras como kilómetro que aparece siempre como " $\mathrm{km}$ " e igualmente ocurre para hacer referencia a hora que se refleja con el símbolo " $h$ ". Es significativo señalar que en todos los casos en los que se emplean estos símbolos, los emisores nunca dejan un espacio en blanco entre el símbolo y la cifra.

La utilización de acrónimos es también muy habitual. Uno de los acrónimos más asentados entre los usuarios de esta red es el de " $q$ " como forma reducida de te quiero. También hay muchos acrónimos que provienen de estructuras inglesas pero que ya se están asentando entre los usuarios españoles. Algunos ejemplos son "LOL" que es el acrónimo de "Laughing Out Loud", el cual podría traducirse como reírse a carcajadas. Se emplean formas como "WTF" que nace a partir de la expresión anglosajona "What The Fuck". Se trata de un recurso que se utiliza no solo para abreviar, sino también para evitar escribir una palabrota. Para expresar sorpresa, emoción o miedo se usa el acrónimo "OMG" que en inglés se desarrolla como "Oh My God!".

- Se crean nuevas formas de escrituras para ahorrar espacio y tiempo en las que aparecen símbolos matemáticos como " $x$ " para sustituir a la preposición por o en aquellas palabras que contienen esta sílaba.

- Es llamativa la ausencia de /h/. Posiblemente porque se trata de una letra que no se pronuncia por lo que se puede creer que su grafía es innecesaria. Como por ejemplo en "esto a sido", "me a hecho un regalazo" o "no e podido".

- Por último, en la mayoría de intervenciones del corpus, en las que se usan signos de interrogación o de exclamación, el signo de apertura de las frases no se utiliza, este se omite y se emplea solamente el signo de cierre.

Otro aspecto fonético-ortográfico es la imitación del habla popular como en "mi arrrma".

La ortografía fonética se produce especialmente en los términos extranjeros. Pues la oralidad que caracteriza el lenguaje de las redes sociales densas y múltiples conlleva que muchas palabras se escriban como se pronuncian, como es el caso de los vocablos ingleses "bully", "feisbuc", "Beibi" o "gudnight" o "graxie". 
Una característica que está presente en casi todos los individuos analizados es el alargamiento silábico o vocálico. Este se emplea con una finalidad suprasegmental ya que actúa como refuerzo exhortativo por lo que está muy relacionado con la entonación. Estos alargamientos son un recurso para mostrar en la escritura lo que en la oralidad se traduciría como una pronunciación enfática y remarcada. Habitualmente se utiliza en las funciones expresivas o emotivas para mostrar alegría y sorpresa, o en el caso contrario, para mostrar enfado o insistencia. Encontramos ejemplos como: "cenitaaaa", "comeeeer", "teequiiieeerooooo", "mamiiiii", "por fiiiiin", "tiempoooo", "soooiiiiiis", "vamoooos", "muиuuy". Además, este alargamiento se produce también con algunas consonantes como la/s/: "compraaaasss", "campanassss" o "gussssta".

Otro rasgo fónico que se refleja en la escritura es la pérdida de la [d] intervocálica: "quedao", "aburrío" o "estamos preparaos".

El último rasgo fónico reseñable es la sustitución de la /-d/ final por la vibrante simple /-r/ en los imperativos plurales, como ocurre en "votar" por votad.

Centrándonos en los rasgos puramente ortográficos que se producen sin influencia de la fonética, debemos hacer referencia al poco uso de la mayúscula al principio de oración. En muchos casos, las mayúsculas ni siquiera se utilizan en nombres propios de personas como es el caso de "vane", ni en topónimos como "mallorca", ni en nombres propios de lugares "hogwarts" o en empresas como el nombre del mismo Facebook, término que encontramos en repetidas ocasiones escrito con minúsculas.

En la ortografía de los mensajes escritos en castellano se observa la influencia del catalán como por ejemplo "el q me faltava por ver" de la frase hecha catalana el que em faltava per veure, o el uso de la $i$ latina como conjunción, en lugar de usar la y griega "los cursos gratis $i$ a los dos minutos". También se observan influencias del castellano en la escritura en catalán.

Por último, en cuanto a ortografía, los usuarios de redes densas y múltiples omiten en infinidad de ocasiones las reglas de acentuación.

\section{Rasgos léxicos}

En términos generales, podemos considerar que el léxico que usan los individuos que pertenecen a una red densa y múltiple es bastante reducido y muy común. 
Se usan muy pocos sinónimos que aporten matices y destaca la repetición de las mismas palabras en intervenciones muy cortas.

Es frecuente el uso de palabras comodín o palabras baúl, es decir el uso de términos que se emplean con multitud de sentidos y que reemplazan a otras palabras que serían más precisas. Hay un uso excesivo de verbos como hacer, tener, haber, poner, poder o decir. El término cosa se emplea para designar cualquier circunstancia u objeto, y los adjetivos bueno, malo y bonito son los más recurrentes entre individuos de redes fuertes.

El léxico se caracteriza por expresar emociones, ser sugestivo y en ocasiones ambiguo. Se trata de un lenguaje que permite una gran variedad de lecturas y que se puede emplear de forma simbólica, de manera que no transmite únicamente una información, sino que mediante él se trasladan, de forma implícita, sensaciones y sentimientos. Este tipo de lenguaje solo es posible utilizarlo en redes múltiples y densas, porque el emisor se asegura, gracias a los vínculos que tiene con los receptores, que estos van a saber interpretar de la manera que él quiere el mensaje que les está transmitiendo.

Es abundante el uso de frases hechas y metáforas de la vida cotidiana, como por ejemplo: "se le ha dado mucho bombo", "los pelos de punta", "familia unida jamas será vencida".

Son numerosas las palabras que proceden directamente del argot juvenil, como por ejemplo "currar", "molar", "tio", "paridas", "chorrada" o "parida"; los vulgarismos como "ni puta idea", "tipa" o "mierda"; e incluso los insultos como "idiotas", "inútiles" o "cabroneeeees".

El último aspecto léxico que debemos señalar es el descomunal uso de extranjerismos. Hay algunas palabras que se toman de otros idiomas en los que la forma es más corta que en español, demostrando, otra vez más, que la brevedad es un rasgo que los usuarios buscan constantemente. Uno de los casos más extendido es el de "ok". De la misma manera se puede entender el empleo de las palabras "on" y "off". Por otro lado, se emplean infinidad de palabras y de expresiones que tienen traducción en español pero que la fuerte presencia del inglés está relegando a un segundo lugar. Algunos de estos casos son: "troll", "go", "crack", "playback", "merchandising", "marketing", "friki", "show" o las expresiones "welcome to paradise" y "home, sweet home!", entre muchas otras. 


\section{Rasgos morfosintácticos}

Desde el punto de vista gramatical, una de las características más significativas es la estructura de las oraciones. Predominan las frases simples y en voz activa. Las construcciones son cortas y, en algunos casos, incompletas. Se producen muchas elipsis, posiblemente de forma involuntaria y como consecuencia de la celeridad del pensamiento. Hay oraciones suspendidas de manera voluntaria mediante los puntos suspensivos como "Xosq ... mencanta la foto".

La sintaxis no responde al orden lineal basado en el orden canónico de constituyentes, sino que los constituyentes se sitúan de forma estratégica para resaltar lo que más interesa: "foto orla, ya queda poquito", "buena vida, como me acuerdo de ti", "color y más color, esto es lo que viene esta temporada". A veces, la dislocación se produce a la derecha. Se trata de elementos que se añaden como explicación, matización o precisión a la información dada: "gran boda la de anoche con los mejores, enhorabuena pareja", "un poco tarde y a falta de ir mejorándolo, nuestro primer árbol ya está".

Se produce una gran concatenación de enunciados que se acumulan sin ser interdependientes entre ellos. Se trata de añadirlos a medida que le vienen al hablante a la mente, en un intento de ir explicando ideas anteriores y proporcionar detalles de las mismas.

Otra particularidad que se desprende de la poca organización y planificación de los enunciados es la aparición de los anacolutos. La mayoría de veces, están producidos por las necesidades del emisor de reelaborar lo que está expresando. Estos errores vemos que pueden afectar tanto al léxico como a la gramática. En el sentido gramatical se usa para matizar o cambiar una voz, o modificar alguna función sintáctica, o el tiempo, el modo, etc., aquí derivan también las autocorrecciones o reinicios de oraciones. Este aspecto es relevante para caracterizar las relaciones entre individuos, ya que si los vínculos no fueran fuertes, el emisor reelaboraría o cambiaría su comentario antes de emitirlo.

Otro aspecto que se observa con mucha frecuencia entre este grupo de individuos es el uso de oraciones exclamativas y desiderativas. Estas modalidades se emplean con la finalidad de expresar emociones y sentimientos de manera que mediante su lectura el receptor del mensaje puede saber el estado de ánimo del emisor.

La conversación que se establece en la red fuerte se caracteriza por ser muy egocéntrica. La figura del emisor está muy presente, ya sea de forma explícita 
o implícita. Esto conlleva que en muchas estructuras podamos localizar elementos deícticos de persona. De hecho, es frecuente el uso de los pronombres y determinantes personales de primera y segunda persona: "yo iba a salir y me lie", "yo voto que si", "nosotros si lo hicimos".

Respecto a la morfología, destaca el frecuente uso de aumentativos $\mathbf{y}$ diminutivos: "ratito", "ayudita", "solecito", "descansillo", "visitilla", "bellezón", "guapetona", "regalazo", "besazos".

Destacan distintas técnicas de intensificación para marcar expresividad en el discurso: "súper enhorabuena", "eternamente agradecida", "fiesta a tope", "un montón", "nunca nunca fallará", "una ocasión única única".

Otro medio importante para darle más fuerza expresiva al contenido del mensaje son las estructuras comparativas de superioridad. En ellas aparece de forma fija el cuantificador tan, tanto, más, menos, etc. y el elemento cuantificado, que es el tema del que se habla y al que se le quiere dar el valor superlativo, como ocurre por ejemplo en "esta pulsera tan xula" o "me ha gustado tanto y me ha traído tan buenos recuerdos".

En cuanto a las formas verbales que más predominan en este tipo de red son aquellas que están en primera o segunda persona del presente o pretérito perfecto del modo indicativo. Este modo verbal se usa para designar y describir hechos o acciones concretas y reales siendo esta una de las finalidades principales entre los sujetos que forman parte de una red fuerte. Ahora bien, también se usa con frecuencia el modo subjuntivo, ya que son frecuentes las oraciones desiderativas o hipotéticas. Además, existe una tendencia bastante generalizada de utilizar el gerundio, aunque en algunos casos se caiga en el error de emplearlo con posterioridad o como una consecuencia de la acción principal. El modo imperativo y los tiempos condicionales se emplean muy poco.

\section{Rasgos Pragmáticos}

A algunos rasgos de tipo pragmático ya hemos hecho referencia en los puntos anteriores, pues muchas de sus características se construyen mediante el léxico, la fonética o las estructuras gramaticales.

Uno de los aspectos importantes es el uso de intensificadores. Estos son recursos lingüístico-pragmáticos que se manifiestan en todos los niveles y dimensiones del lenguaje. Sirven para conseguir que los mensajes escritos 
transmitan más de lo que realmente se expresa con el léxico y la gramática. Con ellos el individuo no manifiesta únicamente sus ideas, sino que impone su afectividad para influir de modo persuasivo en su receptor.

Resulta difícil encontrar estrategias de cortesía, ya que no existe ningún interés por parte de los sujetos por establecer distancia entre ellos ya que todos están en el mismo nivel.

En las redes densas y múltiples predomina la función emotiva y expresiva, ya que una de las principales finalidades de estas comunicaciones es transmitir emociones, estados anímicos, sentimientos y opiniones subjetivas. Por ello, para conseguir que la comunicación sea enfática y expresiva se utilizan muchas oraciones interrogativas y exclamativas, así como diferentes recursos léxicos, como puede ser el uso de vulgarismos, insultos, expresiones malsonantes, y de vocabulario afectivo que se repite constantemente (guapa, cariño, amor, persona esencial, te quiero, besos, tete, amigo, bella, crack, etc.)

Las onomatopeyas son otro modo de darle viveza a los mensajes. Esta técnica hace que el receptor al leer la intervención pueda imaginar la producción y realización del sonido. De esta forma la interacción escrita cobra sensación de oralidad, cercanía y, sobre todo, de realidad: "Jo", "Ai, ai, ai" ,Woooo", "Tic tac tic tac", "Txaaantxaaan", "Oooh", "Yeeee", "Shhhhhh", "Eehh", Ñamñam", Mmm", "Oleeee", "Fiiuuufiiiuuuu", "Ah", "Buah", "Muaaa", "Ppff", "Jajajaja". La mayoría de estos ejemplos de onomatopeyas contienen un alargamiento vocálico y/o una repetición del término que la compone con la finalidad de intensificar más su función, incluso en muchos casos, construyen estructuras exclamativas para potenciar su expresividad y realismo.

Por último, nos centramos en el paralenguaje, el cual juega un papel decisivo en la comunicación. La comunicación gestual sirve para compensar los errores de cohesión y coherencia, pero el lenguaje empleado en las redes sociales no permite mostrar elementos cinésicos y proxémicos, como expresiones faciales, gestos, distancia entre individuos o posturas corporales. Esta carencia de la lengua escrita llevó a la aparición de los emoticonos, combinaciones de diferentes signos de puntuación y símbolos que se aplican con el fin de mostrar la expresión de una emoción en el rostro. Se escriben formando una única secuencia en línea y se colocan después del último signo de puntuación de cada frase. Hasta el momento de su aparición, el lenguaje escrito estaba dominado única y exclusivamente por vocales, consonantes y signos de puntuación. Los emoticonos se han incorporado rápidamente y se han extendido con mucha 
facilidad porque proporcionan un toque más humano y real a la comunicación informatizada, además de añadir matices y riqueza a las frases al incorporales información emocional.

Una gran ventaja de los emoticonos es que se han adoptado de forma universal lo que posibilita el entendimiento entre individuos de diferentes idiomas y reducen la ausencia de un canal visual en la conversación.

La aparición de los emoticonos está relacionada con la inmediatez que caracteriza a las interacciones en las redes sociales. En la escritura tradicional existe un margen de tiempo que permite al sujeto construir oraciones de forma que su actitud personal quede clara. Pero un mensaje construido rápidamente es muy probable que tenga carencias, y que presente enunciados bruscos, toscos y que dan lugar a mal entendidos. Para evitar estas situaciones se emplean los emoticonos, los cuales distienden la situación y son una forma de evitar las ambigüedades y preocupaciones erróneas que surgen cuando se exige el lenguaje escrito que traslade la carga de significado que le corresponde al habla (Crystal 2012: 53).

La rapidez, poca premeditación y dinamismo en la conversación hacen que los emoticonos sean un rasgo muy presente en el corpus analizado.

\subsection{Redes Laxas: Redes Poco Densas y Simples}

Las redes laxas se caracterizan por las diferencias existentes entre los actores que conforman la relación, ya que estos no siempre comparten sus características sociales. Además, hay que tener en cuenta los pocos puntos de encuentro que unen a los actores. Estas características dan lugar a una comunicación poco relajada que es fruto de la escasa confianza que existe entre ellos. El conocimiento unilateral, en la mayoría de ocasiones, y la poca o nula experiencia común compartida por los personajes son factores determinantes en el comportamiento lingüístico de este tipo de red.

El rasgo más significativo que se observa entre los actores que se mueven en redes con valores bajos de multiplicidad y densidad es que su comportamiento lingüístico es muy similar a los patrones establecidos por la norma estándar, es decir, se sigue lo que está fijado por la convención social como correcto (Lara 1976: 32).

El tipo de vínculo establecido implica el uso de un estilo formal, habitual cuando se entabla una comunicación con desconocidos y propio de situaciones 
en las que no existe un ambiente de confianza entre los interlocutores y se pretende mostrar respeto.

Los emisores desean ser correctos, pues saben que están siendo observados por personas que no conocen y al mismo tiempo, pretenden ser cercanos y amables para así mantener a sus seguidores. Su propósito es encontrar un punto intermedio entre el registro coloquial y el registro culto.

La formalidad se refleja en la restricción temática. Los temas que se tratan no suelen ser personales, sino relacionados con el ámbito en el que el actor está especializado. Esta temática es la que motiva a los receptores a formar parte de la red del emisor, ya que comparten interés por determinados temas.

La comunicación en las redes laxas no es dinámica ni espontánea. Por un lado, el emisor no espera ninguna respuesta por parte de los miles de receptores que tiene, sino que su principal intención es difundir sin restricciones una información. Por otro lado, no es una comunicación totalmente espontánea, porque los mensajes se envían con cierta planificación, premeditación y control sobre lo que se está produciendo. El personaje ha escogido los rasgos lingüísticos de su mensaje de forma consciente. El actor se muestra pendiente de la corrección, de seleccionar los recursos que garanticen la cohesión y la coherencia del discurso, y el estilo cuidado y elaborado del mismo.

A partir de estos primeros rasgos generales, es fácil entender que las marcas dialectales y sociolectales tiendan a neutralizarse. En este tipo de estructura los rasgos vernáculos se dejan de lado, ya que los individuos tienen la presión de la opinión que se pueda generar sobre ellos a partir de sus comentarios y las marcas vernáculas están consideradas como inferiores socialmente.

Observamos que las intervenciones de Twitter se apartan en muchos aspectos de las características propias de la oralidad y tienden a identificarse más con las de la escritura. Se busca el desarrollo de un enunciado ordenado y cuidado. Se establece una distancia entre el escritor y el lector.

Recordamos que hemos agrupado a los usuarios de Twitter en tres grupos diferentes, dependiendo del número de seguidores que tengan:

- Grupo 1: formado por actores que tienen entre 655 seguidores y $250 \mathrm{~K}$ (250.000).

- Grupo 2: formado por actores que tienen entre $251 \mathrm{~K}$ y $999 \mathrm{~K}$.

- Grupo 3: formado los actores que tienen más de 1M (1 millón) de seguidores. 
Todas las características que hemos señalado hasta este momento y las que enumeraremos a continuación se presentan de forma más acentuada en el tercer grupo mientras que los mismos rasgos se muestran más suavizados en el primer grupo.

\section{Rasgos Fonético-Ortográficos}

La brevedad es una de las características más importantes de la red social Twitter, pues es el rasgo técnico-formal que más la diferencia del resto de plataformas, ya que esta presenta un límite de caracteres -concretamente 140- por mensaje. Esta limitación debería tener como consecuencia un uso abundante de abreviaciones para ahorrar caracteres y así poder incluir toda la información que se desea en un único tuit, pero no es así. Esto puede deberse a que la abreviatura puede verse como un rasgo informal o coloquial y que posiblemente no todos los receptores sepan interpretar. Con la no utilización de abreviaturas, los actores evitan confusiones y además protegen su imagen, ya que la abreviatura podría ser interpretada como falta de cultura o conocimiento ortográfico. En Twitter prevalece el deseo de crearse una buena imagen mediante una escritura correcta y pulcra sobre la inmediatez. Ejemplos como los siguientes ponen de manifiesto la no abreviación en los mensajes de estas redes: "México D.F." en el que solo con la primera parte hubiese sido suficiente; fechas completas como "3 de marzo"; o los números escritos con letra.

Casi no se observan truncamientos, contracciones, reducciones gráficas, acortamientos, usos de acrónimos o siglas, etc. Es curioso que no aparezcan formas que están bastante arraigadas en la escritura de las redes sociales como los silabogramas que se crean con "que" o "de", los acrónimos como "TQM" o la supresión de los signos de puntuación.

Cabe destacar que de los pocos recursos significativos que podemos encontrar en cuanto al ahorro de caracteres en la escritura es el hecho de omitir el signo de apertura de las frases exclamativas e interrogativas, aunque este no se produce ni en todos los personajes, ni tampoco de forma constante en aquellos que lo presentan en alguna ocasión.

Los rasgos puramente fonéticos que utilizan los individuos de este tipo de estructura reticular son neutros y estándares. No hay ningún rasgo significativo que les caracterice. Pues no aparecen imitaciones del habla popular, ni tampoco términos extranjeros escritos según la fonética. De la misma forma, 
tampoco se presentan desviaciones o sustituciones erróneas causadas por problemas de pronunciación.

El único rasgo fónico propio de las redes sociales que podemos señalar es la aparición de algún alargamiento vocálico o consonántico. Este se usa con una finalidad suprasegmental, pues se trata de un refuerzo entonativo que sirve para transmitir en la escritura una pronunciación entusiasta, como por ejemplo "os vais a enteraaaaaar!!", "Amigos de Chileeeeeeee", "disfrutarlooo", "Muuuuuuuuchaluuuuuuzzzzzzzzz para tod@sssssss".

Desde el punto de vista ortográfico, resulta remarcable la pulcritud y perfección que existe. A partir de las intervenciones de los actores se detecta que estos revisan sus mensajes y tienen en cuenta las normas ortográficas. Debemos hacer referencia al empleo correcto de la mayúscula y minúscula en sus diferentes usos.

Especial cuidado se observa en el uso de los signos de puntuación, que juegan un papel importante para crear una comunicación eficiente y sin ambigüedades. Los signos de puntuación sirven a los emisores para delimitar los enunciados y ordenar las ideas, lo cual demuestra la planificación previa del contenido y la poca espontaneidad en estas redes. Los actores de estas estructuras, a pesar de la restricción espacial y de la tendencia generalizada de las nuevas plataformas de comunicación, siempre emplean los signos de puntuación necesarios. Resulta común el uso del punto seguido, del punto y aparte o la coma, pero observamos que la premeditación de la intervención va más allá y se emplean signos menos usuales y que suelen utilizar en escritos más extensos. Nos referimos al uso del punto y coma "Hoy un gran paso; seguimos trabajando", o el de comillas " «privado»", guiones "proponerle fecha-prontoy lugar" y paréntesis ("(14 y 17 mayo)").

Un símbolo que se repite constantemente en la ortografía de Twitter es el de arroba, el cual se representa con el carácter @. En las intervenciones que hemos analizado se emplea para tres usos diferentes. En primer lugar, se escribe al principio de un tuit para nombrar a quien se dirige, es un sustituto de "a la atención de". En segundo lugar, se emplea para hacer referencia a lugares, empresas, programas de televisión, etc. que cuentan con un perfil en la plataforma. En tercer lugar, se utiliza, gracias a su estructura formal, para hacer referencia a los dos géneros, ya que parece a la vez una a y una o, como vemos en "list@s" o “tod@s". Este último uso sirve para que no predomine ninguno de los dos géneros y no se pueda ofender alguno de los receptores. 
Por último, en este apartado referido a la ortografía debemos hacer mención de la acentuación. Los individuos que forman parte de redes poco densas y simples procuran cumplir por regla general con las normas de acentuación de nuestra lengua.

\section{Rasgos Léxicos}

En términos generales, podemos decir que el código lingüístico empleado por los actores pertenecientes a estructuras reticulares laxas es elaborado. Por ello, el léxico utilizado se caracteriza por ser amplio, completo y variado, garantizando así la riqueza de los comentarios y la precisión al expresar las ideas que se quieren transmitir.

Destaca el uso de sinónimos y la utilización de un gran número de adjetivos que aportan matices proporcionando información extra para hacer más clara la intervención. En la mayoría de ocasiones no aparecen los sustantivos con un único adjetivo, sino que se presentan con varios lo que incrementa más aún la función de estos, como podemos ver en "una artista única, genuina y sorprendente" o "un proyecto muy chulo y emocionante".

En este tipo de red, son abundantes los eufemismos para sustituir palabras consideradas indecorosas o inoportunas que se cambian por otras que la sociedad juzga como más agradables para evitar que algún receptor pueda ofenderse. Algunos ejemplos son: "me desorino", "un concursante dirá adiós".

Por otro lado, se procura que el léxico no sea vago y no caiga en la ambigüedad ya que al existir pocos vínculos con los receptores, el actor no sabe sí estos van a escoger la interpretación que se adecúa a lo que él quiere trasmitir. Por ello, se evitan los refranes y las frases hechas, además de ser estas expresiones con connotaciones informales.

La poca confianza entre los miembros de la red hace que no se utilice léxico argótico, vulgar, ni insultos. Aunque en este caso debemos matizar que se observa claramente la diferencia entre los personajes según el número de seguidores que tienen. Los individuos que hemos clasificado en el tercer grupo, aquellos que su red es totalmente laxa, carecen de este tipo de léxico, pero a medida que la red va siendo más densa y los personajes se sitúan en el segundo y, sobre todo, en el tercer grupo, se dejan ver ciertos rasgos de coloquialidad, e incluso vulgaridad: "majuelos", "zapas", "buen rollo", "putas botellas", "coño", "de mierda". 
El último aspecto léxico que debemos señalar es el uso de los extranjerismos y de los tuits escritos en otros idiomas diferentes del español. Los anglicismos están muy presentes debido al prestigio que se le asigna al inglés: "views", "crack", "reality", "Let's go!".

Por lo que se refiere a los tweets escritos en otros idiomas, destacan los casos de personajes del grupo 3, que escriben sus mensajes de manera simultánea en inglés y en español. Este rasgo es muy particular de estas estructuras reticulares poco densas y simples, ya que los emisores saben que cuentan con muchos receptores de diferentes nacionalidades, pero no conocen quiénes son y por este motivo utilizan el inglés como lengua general para que su información pueda llegar a todos. También existen algunos personajes que escriben el mensaje en un único idioma, en inglés o en español, dependiendo de a quién se dirijan. El mismo comportamiento se observa en personajes de origen catalán que combinan las tres lenguas, catalán, castellano e inglés, según a quién quieran dirigir el contenido del mensaje.

\section{Rasgos Morfosintácticos}

La sintaxis que utilizan los actores de las redes laxas se caracteriza por ser fluida, dinámica y precisa. Las estructuras sintácticas presentan cierta complejidad, están cohesionadas y ordenadas. Lo cual conlleva que no sea habitual encontrar elipsis, enunciados suspendidos, anacolutos, reelaboraciones o redundancias, pues estos son rasgos propios de la comunicación informal, ya que transmiten celeridad en la escritura y poca planificación.

Las frases se ordenan de forma lineal basándose en la sucesión de constituyentes formales. Aunque en algunos casos sí que es común que las estructuras se alteren para situar en primer término aquello que el emisor quiere resaltar. Esta característica no se puede entender como una falta de planificación, ya que en realidad es una estrategia del actor para captar la atención de los receptores focalizando lo más llamativo en el inicio: "Tan bonita es San Sebastián", "ganazas las que tengo de veros", "después de varias horas arreglando la radio estamos de nuevo on", "Un honor formar parte de este gran número".

Las ideas se estructuran de forma jerárquica. Esta gradación suele estar organizada mediante el uso de oraciones compuestas o subordinadas que se enlazan entre sí gracias al empleo de conectores y conjunciones. Aparecen 
muchos nexos, conectores y organizadores textuales que se encargan de unir las oraciones, jerarquizarlas, estructurarlas e introducir información nueva de forma coherente. Las oraciones coordinadas, así como las palabras y los sintagmas independientes aparecen unidos mediante nexos copulativos, disyuntivos y adversativos. Las oraciones subordinadas se unen a su oración principal mediante nexos subordinantes de diferente tipo: lugar, tiempo, modo, comparativos, causales, finales, etc.

Se observa el uso de diversa tipología oracional. Las oraciones enunciativas afirmativas son las que más aparecen en este tipo de red. Pues los actores quieren transmitir a sus receptores una información de forma objetiva. Las oraciones interrogativas, en la mayoría de casos, son retóricas, pues el emisor lanza la pregunta pero no espera una respuesta ni de un receptor en concreto, ni de todos los lectores. Se utilizan como mecanismo para llamar la atención de los seguidores y para transmitirles la información de forma más vistosa: "¿Te gustaría hacer la bibliografía de la Nouvelle Cuisine? ¡Participa!”, "¿Y los españoles? ¿Rien también?". También es común encontrarnos con oraciones exclamativas mediante las que los personajes expresan emociones y sentimientos, en este caso siempre positivos: "¡Viva Huelva!", "iiQué suerte tengo de tener esta Familia!!!”, "¿Qué programón!”. Las oraciones desiderativas expresan un deseo o suplica de forma indirecta y en ellas el emisor está muy involucrado, pero en las redes de densidad baja y escasa multiplicidad estas características varían. Es el actor el que desea pero nunca es un deseo personal, sino que se trata de un aspecto general y en el que se implica a los receptores, o incluso a toda la sociedad: "Ojalá, algún día, se admire, se respete y sirvan de ejemplo aspiracional todas esas personas", "Ojalá no existiera este dia, querría decir que tenemos los mismos derechos".

Los enunciados que se emiten en las redes laxas tienen muy poca presencia del pronombre personal "yo". Se prefiere el uso de determinantes y pronombres personales en primera persona del plural o las formas impersonales: "no pueden con nosotros", "estaremos en el Carnaval", "se echa de menos". Estas opciones tienen una función pragmática clara ya que al incluir a los receptores, sirve como estrategia para mostrar cercanía.

Otro rasgo morfológico que apreciamos, y que tiene un significado pragmático, es el uso de aumentativos y diminutivos, que se emplean como intensificadores del lenguaje y sobre todo, para mostrar cierta cercanía e intentar superar las barreras que hay entre los actores. A pesar de ello, este tipo de red no se caracteriza por un uso masivo de este recurso. 
En este tipo de redes, no se observa, sin embargo, como técnica de intensificación la reduplicación de adjetivos, adverbios o sustantivos.

El modo verbal que predomina es el indicativo, pues el propósito comunicativo de sus usuarios es transmitir información y describir hechos o acciones concretas.

Uno de los rasgos verbales más significativos en este tipo de red es el del uso de la voz pasiva y el uso de verbos modales de creencia, duda o probabilidad.

\section{Rasgos Pragmáticos}

Uno de los recursos pragmáticos que caracteriza las emisiones de las redes poco densas y simples es el uso de elementos de cortesía. Los actores utilizan las formas establecidas por la sociedad como recursos lingüísticos adecuados para crear cordialidad, mostrar respeto y evitar conflictos. Algunas de estas formas son los saludos, disculpas y formas de cortesía: "buenos días", "hasta pronto", "perdón", "pido disculpas", "por favor", "gracias".

Se emplean bastantes figuras retóricas con una finalidad pragmática:

- La personificación que consiste en atribuir cualidades o acciones propias de seres humanos a otros elementos que no las poseen por no ser individuos, como por ejemplo "tiempo londinense, se va a portar bien usted conmigo?", "despertáis mi sonrisa".

- La metonimia, figura retórica que consiste en designar una cosa con el nombre de otra con la que existe una relación: "estrenando mi nueva Polaroid", "Vamos a hacer un Periscope".

- La sinestesia es una figura que mezcla sensaciones de distintos sentidos entre ellos o con sentimientos: "me sabe el alma", "La victoria 400 con una tarta sabe mejor".

- La metáfora identifica un término real con otro imaginario, entre los que hay una relación de semejanza. Esta figura retórica es una herramienta que permite transmitir ideas complejas o reflexiones: "el q no se pinche con las espinas es que tampoco disfrutó el olor de la flor", "tú eres la estrella", "toda comunidad debe ser un oasis de caridad", "Golazos con la pólvora mojada". 
Otro recurso pragmático que destaca es el empleo de vocabulario afectivo, emotivo, cariñoso y afable. Por el contrario, son prácticamente inexistentes las expresiones desagradables o insultantes.

La atenuación es una estrategia pragmática con la que se mitiga la fuerza del mensaje, se minimiza el efecto de lo que se va decir o se ha dicho, y tiene como principal finalidad no crear tensión o enemistad en los receptores, pues se busca la mayor aceptación por parte de estos. Esta estrategia se consigue mediante diferentes recursos como cuantificadores que minimizan el contenido ("un poco", "solo", "tan solo"), fórmulas aproximativas ("prácticamente", "casi", "aproximadamente"). De la misma manera, son atenuadores del discurso los mecanismos de despersonalización como "por lo visto". La risa puede servir para atenuar una opinión y minimizar las connotaciones negativas de un enunciado. Otro mecanismo es el entrecomillado de algún término, de manera que el significado de la palabra se modifica y se entiende de forma más sutil: "suculentos pagos". A estas estrategias, hay que añadir los eufemismos, el vocabulario afectivo y los diminutivos, así como los verbos y adverbios de pensamiento duda y probabilidad, y la impersonalización del sujeto mediante el uso de pronombres impersonales.

Destaca el poco uso de onomatopeyas y no predominan los alargamientos vocálicos o las repeticiones de letras, pues no hay intención de intensificar el realismo que estas ya ofrecen.

Finalmente, nos centramos en el paralenguaje, el cual es escaso entre los usuarios de Twitter, pues entre ellos vemos que hay muy pocos símbolos y emoticonos. Esta carencia se debe a que una de las funciones de la comunicación gestual es la de compensar los errores de cohesión y coherencia, algo que no se presenta habitualmente en la comunicación de redes laxas. Además, el empleo de emoticonos lleva asociada la idea de informalidad y coloquialidad, dos características que no son propias de este tipo de estructura reticular.

\section{Conclusiones}

El objetivo fundamental de esta investigación ha sido aplicar el modelo de redes sociales, propuesto por Milroy en 1987, al análisis de las interacciones lingüísticas a través de plataformas digitales como Facebook y Twitter.

Hemos partido de la importancia que tienen las estructuras sociales para los sujetos, pues necesitamos y dependemos de la presencia del otro y de la 
interacción con él. No nos aislamos ni vivimos de forma individual, sino que nos organizamos en estructuras reticulares que nos permiten formar parte de la sociedad e interactuar en y con ella. El concepto de red social ha sido estudiado por diversas disciplinas a lo largo de la historia. La sociología fue la primera disciplina que se interesó por las redes sociales de los individuos. De sus investigaciones se desprende que el conjunto de actores de la sociedad están conectados entre sí por diferentes tipos de vínculos que construyen la estructura social. Este entramado de lazos interpersonales es un mecanismo que posteriormente la sociolingüística toma con la finalidad de estudiar el lenguaje en la sociedad. Finalmente nace la gran red, Internet, que recoge la idea inicial de las redes sociales. Los social media presentan estructuras sociales compuestas por varios individuos que están conectados por uno o varios vínculos, con la novedad de conectar a sujetos entre sí mediante plataformas digitales que superan cualquier barrera física.

Partiendo de la definición de red social propuesta en los distintos ámbitos analizados, hemos determinado y caracterizado los diferentes tipos de redes sociales que se forman en la comunicación a través de plataformas digitales como Facebook y Twitter. Nuestro análisis nos ha llevado a proponer dos tipos de estructuras reticulares diferentes que se identifican con cada una de las plataformas digitales mencionadas:

1. Por un lado, los usuarios de Facebook presentan una red fuerte, es decir, densa y múltiple. En ellas, el actor está vinculado a un gran número de personas a las que conoce y que, a su vez, se conocen entre ellas. Estas personas están unidas por más de un vínculo. Se trata de redes estables, homogéneas y relativamente pequeñas.

2. Por otro lado, los internautas que emplean Twitter ofrecen una red laxa, que presenta una estructura poco densa y simple. El actor forma parte de una red en la que sus miembros no suelen mantener ninguna relación entre sí más allá del vínculo que les une, es decir, el propio sujeto protagonista de la red. Estas redes son grandes, heterogéneas, poco estables y unilaterales.

El hecho de intentar categorizar los tipos de red en dos grandes grupos puede parecer, en un primer momento, reduccionista. Ahora bien, la lista que aquí se ofrece no es una lista de características absolutas y discretas, sino que existe una gradación entre los actores y los vínculos que estos establecen con el resto de individuos de su red. Esta gradación la podemos ver de forma más 
clara mediante el eje de la Figura 2, el cual demuestra que no únicamente existen dos puntos opuestos en cuanto a las estructuras reticulares, sino que hay puntos intermedios y transitorios en los que las características lingüísticas señaladas en la tabla posterior se mezclan y difuminan sus límites.

\begin{tabular}{|c|c|c|c|}
\hline $\begin{array}{l}\text { RED TOTALMENTE } \\
\text { DENSA }\end{array}$ & RED DENSA & RED LAXA & $\begin{array}{r}\text { RED TOTALMENTE } \\
\text { LAXA }\end{array}$ \\
\hline Facebook & Twitter & Twitter & Twitter \\
\hline $\begin{array}{l}\text { Amistades en } \\
\text { la vida real }\end{array}$ & $\begin{array}{l}\text { Grupo1 } \\
\text { (hasta } 250.000 \\
\text { seguidores) }\end{array}$ & $\begin{array}{c}\text { Grupo } 2 \\
(250.000 \text { a } 1 \\
\text { millón de seguidores) }\end{array}$ & $\begin{array}{r}\text { Grupo } 3 \\
\text { (más de } 1 \text { millón } \\
\text { de seguidores) }\end{array}$ \\
\hline
\end{tabular}

Fig. 2. Eje 1. Línea de los distintos tipos de red que existen relacionados con los social media estudiados.

Tras realizar el análisis podemos proponer una caracterización lingüística de los dos tipos de redes identificados. Esta se presenta en la Tabla 1. La caracterización de los dos tipos de estructuras reticulares nos muestra el gran contraste que existe entre ellas en muchos aspectos fónicos, ortográficos, morfológicos, gramaticales y pragmáticos.

A partir de la caracterización propuesta, podemos comprobar si los principios generales defendidos en los estudios reticulares aplicados a la variación lingüística se cumplen en el lenguaje utilizado en redes sociales como Facebook y Twitter. El análisis del corpus recopilado muestra que estos principios se cumplen en el lenguaje utilizado en las redes sociales virtuales. Existen diferencias fundamentales entre uso del lenguaje en los usuarios de Twitter y en los de Facebook, es decir, entre individuos que forman parte de una red densa y múltiple frente a los que pertenecen a una red laxa. Nuestros resultados muestran que existe una relación clara entre el lenguaje de un hablante y la estructura de su red social.

\section{Bibliografía}

1. Abad, M. (2012). ¿Cómo influyen las redes sociales en el lenguaje? Yorokobu. Recuperado el 10/02/2016, de www.yorokobu.es/\%C2 \%BFcomo-influyen-lasredes-sociales-en-el-lenguaje/

2. Asociación Española de Economía Digital (2012). Estudio Uso de Twitter en España. Barcelona. Recuperado el 21/01/2016, de http://es.slideshare.net/adigitalorg/adigital-estudio-usotwitterenespaa2012def 


\begin{tabular}{|c|c|}
\hline RED DENSA Y MÚLTIPLE: FACEBOOK & RED LAXA Y SIMPLE: TWITTER \\
\hline Elaboración espontánea y sin revisión & Elaboración premeditada y revisada \\
\hline Registro coloquial & Registro estándar \\
\hline Tono informal & Tono formal \\
\hline Temática personal & Temática concreta y especializada \\
\hline Se busca una respuesta & Se busca difundir una información \\
\hline $\begin{array}{l}\text { Uso de las normas locales y presencia de } \\
\text { rasgos vernáculos }\end{array}$ & $\begin{array}{l}\text { No utilización de marcas dialectales y/o } \\
\text { sociolectales }\end{array}$ \\
\hline Muchas abreviaturas & Pocas abreviaturas \\
\hline Imitación fónica del haba popular & Rasgos fónicos neutros y estándares \\
\hline $\begin{array}{c}\text { Muchos recursos fónicos con intención } \\
\text { suprasegmental }\end{array}$ & $\begin{array}{c}\text { Pocos recursos fónicos con intención } \\
\text { suprasegmental }\end{array}$ \\
\hline $\begin{array}{l}\text { Uso erróneo de las mayúsculas y } \\
\text { minúsculas }\end{array}$ & $\begin{array}{l}\text { Uso correcto de las mayúsculas y } \\
\text { minúsculas }\end{array}$ \\
\hline Acentuación nula & Acentuación correcta \\
\hline Puntuación escasa & Puntuación adecuada \\
\hline Léxico común y reducido & Léxico amplio y variado \\
\hline Léxico connotativo & Léxico referencial \\
\hline Repeticiones & Sinónimos y adjetivos \\
\hline $\begin{array}{l}\text { Extranjerismos por ser breves y } \\
\text { modernos }\end{array}$ & $\begin{array}{c}\text { Extranjerismos por ser términos más } \\
\text { universales }\end{array}$ \\
\hline Oraciones simples & Oraciones subordinadas y coordinadas \\
\hline Sintaxis no lineal & Sintaxis lineal y organizada \\
\hline $\begin{array}{l}\text { Construcciones suspendidas, } \\
\text { incompletas, elipsis y anacolutos }\end{array}$ & $\begin{array}{c}\text { Construcciones con nexos, conectores y } \\
\text { organizadores del discurso }\end{array}$ \\
\hline Oraciones exclamativas y desiderativas & $\begin{array}{c}\text { Oraciones enunciativas, interrogativas, } \\
\text { exclamativas y desiderativas }\end{array}$ \\
\hline $\begin{array}{l}\text { Presente de indicativo, pretérito perfecto, } \\
\text { modo subjuntivo y formas en gerundio }\end{array}$ & $\begin{array}{c}\text { Presente de indicativo, pretérito perfecto, } \\
\text { verbos modales y voz pasiva }\end{array}$ \\
\hline $\begin{array}{l}\text { Intensificadores y atenuantes para influir } \\
\text { de modo persuasivo en el receptor }\end{array}$ & $\begin{array}{l}\text { Intensificadores y atenuantes para buscar } \\
\text { la aceptación del receptor }\end{array}$ \\
\hline No se emplean formas de cortesía & Se empelan formas de cortesía \\
\hline Muchas onomatopeyas & Pocas onomatopeyas \\
\hline Muchos emoticonos & Pocos emoticonos \\
\hline
\end{tabular}

Tabla 1. Características lingüísticas que predominan en cada tipo de red.

3. Ayala, E.S., Jiménez, A.J.G. \& Boluda, R.M.Z. (eds.) (2012). El poder de la comunicación en una sociedad globalizada. Almería: Universidad Almería.

4. Barnes, J. A. (1969). Networks and political process. In Mitchell, J.C. (ed.), Social networks in urban situations (pp. 51-76). Manchester: Manchester University Press.

5. Barrera, L. F. (2007). El chateo desde la ciberligüística. Argos, 24(46): 25-37. 
6. Bavelas, A. (1948). A Mathematical Model for Group Structure. Applied Antropology, 7(3): 16-30.

7. Berger, P. L., Luckmann, T. \& Zuleta, S. (1968). La construcción social de la realidad. Buenos Aires: Amorrortu.

8. Berlanga, I. \& Martínez, E. (2010). Ciberlenguaje y principios de retórica clásica. Redes sociales: el caso Facebook. Revista Venezolana de Información, Tecnología y Conocimiento, 7(2): 47-61.

9. Bott, E. \& Arribas, R. G. (1990). Familia y red social: roles, normas y relaciones externas en las familias urbanas corrientes. Madrid: Taurus Ediciones.

10. Bott, E. [1957] (1990). Familia y red social. Madrid: Taurus.

11. Bourdieu, P. [1975] (1984). Capital et marché linguistiques. Linguistische Berichte, 90: 3-24.

12. Boyd, D. \& Ellison, N.B. (2007). Social network sites: Definition, history, and scholarship. Journal of Computer-Mediated Communication, 13(1): 210-230.

13. Caldevilla, D. (2010). Las Redes Sociales. Tipología, uso y consumo de las redes 2.0 en la sociedad digital actual. Documentación de las ciencias de la información, 33: 45-68.

14. Cambra, T. (2010). Facebook y los trastornos de la media(ción) tecnológica en la socialización. In Crisis analógica, futuro digital: Actas del IV Congreso Online del Observatorio para la Cibersociedad. Barcelona: Meddia, cultura i comunicació.

15. Canales, A. B. (2000). Redes sociales y variación sociolingüística. Reis, 91: 115135.

16. Cedergren, H. (1983). Sociolingüística. In López Morales, H., Introducción a la lingüistica actual (pp. 147-165). Madrid: Playor.

17. Cervantes, M.C.L. (2005). Innovaciones metodológicas y nuevos objetivos en sociolingüística. Interlingüistica, 16: 657-666.

18. Coseriu, E. (1981). Lecciones de lingüistica general. Madrid: Gredos.

19. Crystal, D. (2012). El lenguaje e Internet. Cambridge: Akal.

20. De Rivera, J. (2010). La socialización tecnológica: la expresión de la identidad personal y nuevas formas de la relación social en las redes sociales de Internet. Proyecto de investigación, Departamento de Sociología IV. Madrid: UCM.

21. De Rivera, J. (2010). Presentación del Estudio Twitter -Simetría, meritocracia e interprofesionalidad". In Sociología y redes sociales. Proyecto de investigación sobre la comunicación online. Recuperado el 12/02/2016, de http://sociologiayredessociales.com/2010/02/presentacion-del-estudio-twittersimetria-meritocracia-e-interprofesionalidad/

22. De Rivera, J. (2010). Definición de red social en Internet: el contexto de la identidad digital. En Sociología y redes sociales. Proyecto de investigación sobre la comunicación online. Recuperado el 11/02/2016, de http://sociologiayredessociales.com/2010/04/definicion-de-red-social-enInternet -e-identidad-digital/ 
23. De Rivera, J. (2010). Redes sociales y "redes sociales". En Sociología y redes sociales. Proyecto de investigación sobre la comunicación online. Recuperado el 12/02/2016, de http://sociologiayredessociales.com/2010/10/redes-socialesy-redes-sociales/

24. De Rivera, J. (2011). Las Redes Sociales: terminología en torno al fenómeno. En Sociología y redes sociales. Proyecto de investigación sobre la comunicación online. Recuperado el 11/02/2016, de http://sociologiayredessociales.com/2011/05/las-redes-sociles-terminologiaen-torno-al-fenomeno/

25. Duarte, V., Gamboa, A. \& Arguello, S. (2013). Impacto de las redes sociales en la actualidad. Santander: Tecnológica FITEC Bucaramanga.

26. Escandell, D. (2011). Ciberpragmática en ELE. Aspectos fundamentales para una comunicación digital. In Actas de FIAPE. IV Congreso internacional: La enseñanza del español en un mundo intercultural. Jornadas pedagógicas, 17. Santiago de Compostela

27. Faerman, J. (2010). Faceboom: Facebook, el nuevo fenómeno de masas. Barcelona: Planeta.

28. Finquelievich, S. (2000). Del café de barrio a las redes electrónicas. Las comunidades virtuales como actores sociales en las ciudades. In Finquelievich, S. (coord.), ¡Ciudadanos a la red!. Buenos Aires: Ediciones Ciccus, La Crujía.

29. Fischer, C. S. (1982). To dwell among friends: Personal network in town and city. Chicago: University of Chicago Press.

30. Fishman, J. A. (1979). Sociología del lenguaje. Madrid: Cátedra.

31. Flament, C. P. (1977). Redes de comunicación y estructuras de grupos. Buenos Aires: Ediciones Nueva Visión.

32. Frankenberg, R. (1969). Communities in Britain: Social life in town and country. Harmondsworth: Penguin.

33. García, Marcos. F. (1999). Fundamentos críticos de la sociolingüistica. Almería: Universidad Almería.

34. Granovetter M. (1973). The strength of weak ties. American Journal of Sociology, 78: 1360-1380.

35. Granovetter, M. (1982). The Strenght of Weak Ties: A Network Theory Revisited. In Marsden P.V.\& Lind, N. (eds.), Social structures and network analysis. Beverly Hills: Sage.

36. Harary, F. (1956). Structural balance: a generalization of Heider's theory. Psychological Review, 63(5): 277-293.

37. Harary, F., Norman, R. Z., \& Cartwright, D. (1965). Structural models: A introduction to the Theory of Directed Graph. Nueva York: John Wiley \& Sons Inc.

38. Harrinson, C. W. (2000). La construcción de las organizaciones sociales como redes múltiples. Política y sociedad, 33: 97-103.

39. Hudson, R. A. (1981). La sociolingüistica. Madrid: Anagrama. 
40. Labov, W. (1966). The Social Stratification of English in New York City. Washington: Center for Applied Linguistics.

41. Labov, W. (1972). Sociolinguistic patterns. Philadelphia: University of Pennsylvania Press.

42. Lange, B. S. (1977). Iniciación a la sociolingüistica. Madrid: Gredos.

43. Lara, L. F. (1976). El concepto de norma lingüistica. México: El Colegio de México.

44. Lastra, Y. \& Martín Butragueño, P. (2000). El modo de vida como factor sociolingüístico en la ciudad de México. In Martín Butragueño, P. (ed.), Estructuras en contexto. Estudios de variación lingüistica (pp. 13-43). México: Colegio de México

45. López García, Á. \& Morant, R. (1991). Gramática femenina. Madrid: Cátedra.

46. Lozares Colina, C. (1996). La teoría de redes sociales. Papers: Revista de Sociología, 48: 103-126.

47. Macionis, J.J., Plummer, K. (2000). Sociología. Madrid: Pearson Prentice Hall.

48. Manovich, L. (2005). El lenguaje de los nuevos medios de comunicación. Barcelona: Paidós.

49. Marco, M.A. \& Mancera, A.M.C. (2011). De nuevo, sobre los procedimientos de atenuación lingüística. Español actual: Revista de español vivo, 96: 9-40.

50. Milroy, L. (1980). Language and social networks. Oxford: Blackwell.

51. Milroy, J., \& Milroy, L. (1985). Linguistic change, social network and speaker innovation. Journal of Linguistics, 21(2): 339-384.

52. Milroy, L. (1987). Observing and analysing natural language: a critical account of sociolinguistic method. Oxford: Blackwell.

53. Moreno Fernández, F. (1990). Estudios sobre variación lingüistica. Madrid: Universidad de Alcalá de Henares.

54. Moreno Fernández, F. (1990). Metodología sociolingüistica. Madrid: Gredos.

55. Moreno Fernández, F. (1998). Principios de sociolingüística y sociología del lenguaje. Barcelona: Ariel.

56. Moreno Fernández, F. (2011). Internal factors conditioning variation in Spanish Phonology. In Díaz-Campos, M. (ed.), The Handbook of Hispanic Sociolinguistics (pp. 54-71). Cambridge: Blackwell.

57. Online Business School (2015). Estudio Social Media 2015. Recuperado el 29/01/2016, de www.obs-edu.com.

58. Ponce, I. (2012). Redes sociales. Redes Sociales. Observatorio Tecnológico. Recuperado el $31 / 01 / 2016$, de http://recursostic.educacion.es/observatorio/web/eu/Internet /web-20/1043redes-sociales?start $=1$

59. Radcliffe-Brown, A.R. (1940). On social structure. The Journal of the Royal Anthropological Institute of Great Britain and Ireland, 70(1): 1-12.

60. Real Academia Española (2015). Diccionario de la lengua española 23. ed. Madrid: Espasa. 
61. Requena Santos, F. (1991). Redes sociales y mercado de trabajo. Madrid: CIS.

62. Requena Santos, F. (1995). Determinantes estructurales de las redes sociales en los hombres y las mujeres. Papers: Revista de Sociología, 45: 33-41.

63. Requena Santos. F. (2013). Análisis de redes sociales: orígenes, teorías y aplicaciones. Madrid: CIS.

64. Reynoso, C. (2011). Redes y complejidad: Modelos interdisciplinarios en la gestión sostenible de la sociedad y la cultura. Argentina: SB.

65. Romaine, S. (1996). El lenguaje en la sociedad: una introducción a la sociolingüistica. Barcelona: Ariel.

66. Rueda, L.Í. (2011). Análisis del discurso. Manual para las ciencias sociales. Barcelona: Editorial UOC

67. Ruiz, F., Boada, A. B., Sanz, R., \& Camardons, J. S. (2001). Diccionari de sociolingüistica. Barcelona: Encilopèdia Catalana.

68. San Juan, E. (2012). El marco interpretativo de la red social. Revista de Filología, 30: 131-154.

69. Sánchez Burón, A. (2009). Adolescentes en la Red. Estudio sobre los hábitos de los adolescentes en el uso de Internet y las redes sociales. Madrid: Universidad Camilo José Cela.

70. Sankoff, D., \& Laberge, S. (1978). The linguistic market and the statistical explanation of variability. In Sankoff, D. (ed.), Linguistic Variation: Models and methods (pp. 239-249). Nueva York: Academic Press.

71. Santos, F. R. (1989). El concepto de red social. Reis, 48: 137-152.

72. Santos, F. R., \& Muñoz, A. M. Á. (2002). Redes sociales y sociolingüística. Estudios de sociolingüistica: Linguas, sociedades e culturas, 3(1): 71-90.

73. Silva Corvalán, C. (1989). Sociolingüistica: teoría y análisis. Madrid: Alhambra.

74. Simmel, G. (1971). On Individuality and Social Forms. Chicago: University of Chicago Press.

75. Tascón, M., \& Abad, M. (2011). Twittergrafía: el arte de la nueva escritura. Madrid: Los Libros de la Catarata.

76. The Coktail Anlysis (2010). Informe de resultados Observatorio de Redes Sociales. Recuperado el 08/02/2016, de http://www.slideshare.net/TCAnalysis/tca-2ola-observatorio-redes-informepblicov2-2

77. The Social Media Family (2015). El I Estudio sobre los usuarios de Facebook y Twitter en España. Recuperado el 29/01/2016, de www.mediaesfera.com/estudio-sobre-los-usuarios-de-facebook-y-twitter-enespana/

78. Titone, R. (1988). Esiste il 'sessimo linguistico'? In Aebischer, V., Il linguaggio delle donne. Rappresentazioni sociali di una differenza (pp. 9-28). Roma: Armando.

79. Torrego, A. (2011). Algunas observaciones acerca del léxico en la red social Tuenti. Revista Electrónica de Estudios Filológicos, 21. 
80. Vélez Cuartas, G. (2006). El cambio en las redes: una aproximación a las relaciones sociales desde el lenguaje, la representación y la institucionalización. Redes: Revista Hispana para el Análisis de Redes Sociales, 10.

81. Yus, F. (2010). Ciberpragmática 2.0. Nuevos usos del lenguaje en Internet. Barcelona: Ariel.

\section{Author's Biodata}

Esther Juan Escrihuela es graduada en Lengua y Literatura Hispánicas por la Universitat Rovira i Virgili de Tarragona y máster en Formación del Profesorado de Secundaria por la Universidad Católica de Valencia. 